\title{
The adjuvant activity of two urea derivatives on cytokinins: an example of serendipitous dual effect
}

\author{
Federica Brunoni ${ }^{1} \cdot$ Enrico Rolli $^{1} \cdot$ Eugenia Polverini $^{2}$ ([) $\cdot$ Lukáš Spíchal $^{3}$ (D) $\cdot$ Ada Ricci $^{1}$ (1)
}

Received: 2 December 2020 / Accepted: 19 July 2021 / Published online: 25 July 2021

(c) The Author(s) 2021

\begin{abstract}
The aim of this study was to investigate the action spectrum of two urea derivatives, the 1,3-di(benzo[d]oxazol-5-yl)urea (5-BDPU) and the 1,3-di(benzo[d]oxazol-6-yl)urea (6-BDPU). In order to evaluate a possible adjuvant activity on cytokinins the compounds alone or in the simultaneous presence of different cytokinins were assayed either on in vitro typical cytokinin-related bioassays, or on in planta interaction with cytokinin signal transduction pathway. The compounds ability to activate the cytokinin receptor CRE1/AHK4 was studied either by a heterologous bacterial assay or by a competitive binding assay and docking simulations were performed with the crystal structure of the same receptor. Then, owing to their chemical structure which resembles that of urea-type cytokinins, the ability of 5- and 6-BDPU to inhibit the activity of cytokinin oxidase/dehydrogenase of Zea mays (ZmCKX1) was investigated and docking simulations were performed as well. Accordingly to the experimental results, we speculate that BDPUs could show a dual activity: the blocking of the conformational re-adaption of CRE1/AHK4 receptor maintaining the cytokinin inside its binding pocket, thus possibly enhancing its kinase action; the inhibition of cytokinin oxidase/dehydrogenase activity thus possibly preventing its cleavage of natural cytokinins with isoprenoid side chain.
\end{abstract}

Graphic abstract

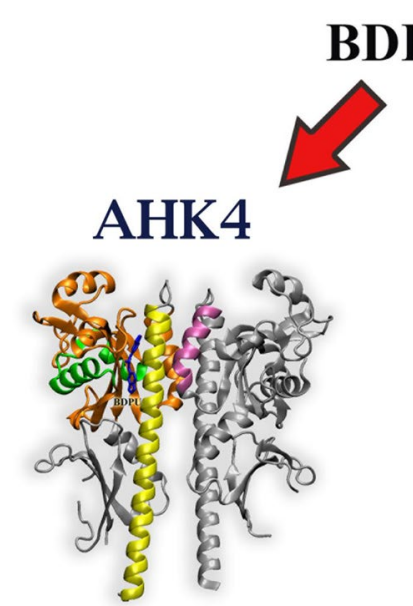

INTERACTION

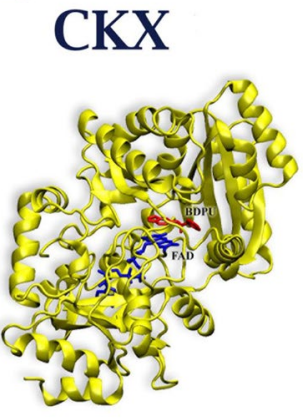

\section{INHIBITION}

Communicated by J. Celenza.

Federica Brunoni and Enrico Rolli contributed equally to this work and should be considered co-first authors.

Extended author information available on the last page of the article 
Keywords Adjuvant activity · Cytokinin · Cytokinin oxidase/dehydrogenase · Cytokinin receptor CRE1/AHK4 · Docking simulation - Urea derivatives

\section{Introduction}

Plant hormones are small bioactive molecules controlling and coordinating a wide variety of physiological processes. Among these chemically different molecules, the naturally occurring cytokinins are $N^{6}$-substituted adenine derivatives, with either an isoprene-derived or an aromatic side chain, playing diverse roles in growth and development throughout plant's life. In fact, they are involved in cell division, shoot and root development, senescence, seed development, response to environmental stresses (Sakakibara 2006). Thus, the endogenous content of active cytokinins in a cell is finely tuned through biosynthesis, $\mathrm{N}$ - or $\mathrm{O}$-conjugation to glucose or irreversible selective degradation (Kieber and Schaller 2014). This latter reaction is catalysed by the cytokinin oxidase/dehydrogenase (CKX, EC 1.5.99.12) that cleaves the unsaturated $N^{6}$-side chains to form adenine and the corresponding aldehyde (Armstrong 1994; Galuszka et al. 2001; Nisler et al. 2016 and references herein). CKX activity has been reported from tissues of several plants, as Zea mays, Arabidopsis, Oryza sativa, Hordeum vulgare, Pisum sativum, Dendrobium sp., showing differences in its expression regulation, cellular localization and substrate affinity (Schmülling et al. 2003; Kopečný et al. 2010). Cytokinins are perceived by redundantly acting histidine kinase receptors, identified in the model plant Arabidopsis thaliana as ARABIDOPSIS HISTIDINE KINASE 2 (AHK2), ARABIDOPSIS HISTIDINE KINASE 3 (AHK3) and CYTOKININ RESPONSE 1 (CRE1/AHK4) (Inoue et al. 2001; Suzuki et al. 2001; Ueguchi et al. 2001; Yamada et al. 2001). They have been assumed to be located in the plasma membrane, while quite recently it has been demonstrated that they are mainly localized in the endoplasmic reticulum at subcellular level, in almost all different plant organs (Caesar et al. 2011; Lomin et al. 2011, 2015, 2017; Wulfetange et al. 2011; Durán-Medina et al. 2017; Romanov et al. 2018).

Since cytokinins have been discovered as cell division promoting factors (Miller et al. 1955), they have been extensively used in in vitro culture of higher plants, as they allow the de novo formation of organs and/or whole plants, by organogenesis and/or somatic embryogenesis (Pierik 1987; Sangwan et al. 1997; Vasil 2008; Duclercq et al. 2011; Trigiano and Gray 2011; Motte et al. 2014). Rather, in tissue culture systems naturally occurring cytokinins are increasingly replaced by some urea derivatives, such as the N-phenyl- $\mathrm{N}^{\prime}-$ (2-chloro-4-pyridyl)urea (CPPU) and the N-phenyl-N'-1,2,3thiadiazol-5-ylurea (Thidiazuron, TDZ), showing improved cytokinin-like activity even if structurally unrelated to adenine derivatives (Gaspar et al. 1996; Ricci and Bertoletti
2009; Trigiano and Gray 2011). About this, it has been demonstrated that these synthetic compounds and some of their derivatives have an intrinsic effect at cytokinin receptor level regardless their different molecular structure, they are not degraded by CKX, they positively affect the endogenous cytokinin concentration in plants inhibiting CKX activity (Schmülling et al. 2003; Nisler et al. 2016, 2021; Hönig et al. 2018; Nisler 2018). Besides, it has been recently reported that some urea derivatives delay leaf senescence, a cytokinin-driven effect, without affecting the cytokinin level, thus demonstrating that this activity of theirs could be due to a cytokinin-independent mechanism, not yet elucidated (Nisler et al. 2018).

Starting from our structure-activity relationship studies, we reported that two symmetrically substituted urea derivatives, the $\mathrm{N}, \mathrm{N}^{\prime}$-bis-(2,3-methylenedioxyphenyl)urea (2,3-MDPU) and the N,N'-bis-(3,4-methylenedioxyphenyl) urea (3,4-MDPU), exert adventitious rooting adjuvant activity without showing auxin-like activity (Ricci et al. 2001a, 2003, 2008) and induce somatic embryogenesis in stigma and styles of Citrus without showing cytokinin-like activity (Carra et al. 2006). Then, modifying the aromatic moiety of these synthetic lead substances by the replacement of the methylenedioxyphenyl groups by the isostere benzoxazole ones, we synthesized the 1,3-di(benzo[d]oxazol-5-yl) urea (5-BDPU) and the 1,3-di(benzo[d]oxazol-6-yl)urea (6-BDPU) (Fig. 1), that have been extensively studied as adventitious rooting adjuvants (Ricci et al. 2006; Brunoni et al. 2014; Ricci and Rolli 2020). Besides, recently, we demonstrated that 5-BDPU acts also as xylogenesis enhancer (Ricci et al. 2016). Here, with the aim of investigating their action spectrum, we tried to verify if their adjuvant activity could have effect on cytokinins, endogenous or exogenously added ones, regardless of being natural adenine-type or synthetic urea-type cytokinins. For this purpose, we analysed the effects of BDPU supplementation in typical cytokininrelated processes by in vitro specific bioassays. Afterwards, in order to elucidate their action mechanism, the in planta interaction of BDPUs with cytokinin signal transduction pathway was evaluated by assaying their effect in Arabidopsis thaliana ARR5::GUS transgenic plants. Then, the interaction of BDPUs with the Arabidopsis cytokinin receptor CRE1/AHK4 was investigated in a heterologous bacterial system and by competitive binding assay. Moreover, due to the availability of the CRE1/AHK4 receptor crystal structure, computational studies of docking simulations were performed to analyse the interaction of BDPUs with it, trying to understand, at the molecular level, their effects in the absence and in the presence of cytokinin. On the other hand, 
<smiles>O=C(Nc1ccc2ocnc2c1)Nc1ccc2ocnc2c1</smiles>

\section{1,3-di(benzo[d]oxazol-5-yl)urea}

\section{5-BDPU}<smiles>O=C(Nc1ccc2ncoc2c1)Nc1ccc2ncoc2c1</smiles>

\section{1,3-di(benzo[d]oxazol-6-yl)urea}

\section{6-BDPU}

Fig. 1 Molecular structure of the urea derivatives used in this study

as to their urea deriving structures and taking into account what already reported about the mode of action of some diphenylurea-derived compounds (Kopečný et al. 2010; Nisler et al. 2016, 2021), to verify if BDPUs could inhibit CKX activity, in vitro enzymatic activity was screened using ZmCKX1 (Houba-Hérin et al. 1999; Morris et al. 1999) and docking simulations were performed with the same crystal structure of ZmCKX1 (Kopečný et al. 2010) and with that of AtCKX7 (Bae et al. 2008), the only crystal structure of AtCKX currently available.

\section{Materials and methods}

\section{Preparation of chemical solutions}

The 1,3-di(benzo[ $d]$ oxazol-5-yl)urea (5-BDPU) and the 1,3-di(benzo[d]oxazol-6-yl)urea (6-BDPU), the N-phenyl$\mathrm{N}^{\prime}$-(1,2,3-thiadiazol-5-yl)urea (TDZ) and the 1,2-benzisoxazole-3-acetic acid (BOAA, used as auxin in the tomato regeneration test (Ricci et al. 2001b)) were dissolved in dimethylsulfoxide (DMSO). The final concentration of DMSO in the in vitro solid or liquid culture medium did not exceed the one considered toxic (0.2\%) (Schmitz and Skoog 1970). The 5-BDPU and the 6-BDPU, synthesized as previously reported (Ricci et al. 2006), were of analytical grade. The aqueous solutions of $\mathrm{N}^{6}$-(2-isopentenyl)adenine (2iP) and 6-benzylaminopurine (BAP) were sterilized by filtration using $0.2 \mu \mathrm{m}$ pore size sterile disposable filter units (Schleicher and Schuell). The trans-zeatin riboside (ZR) was dissolved in $70 \%$ ethanol.

\section{Cytokinin bioassays}

By our previous structure-activity relationship studies we have learnt that these couples of urea derivatives, i.e. 2,3MDPU and 3,4-MDPU first, 5-BDPU and 6-BDPU then, show similar and comparable effects in the different bioassays in which they have been tested. Thus, sometimes, in order to reduce redundant experimental conditions and results, only one of the two couples was used, as reference compound, instead of both (Ricci et al. 2006, 2008; Brunoni et al. 2014). Here the effect of 5-BDPU was assayed on shoot regeneration and on GUS activity in ARR5::GUS transgenic plants as a representative of the group, while in all the other bioassays and in the computational studies of docking simulations both the compounds were taken into account.

\section{Plant development}

Arabidopsis thaliana ecotype Columbia (Col-0) seeds were surface sterilised in $70 \%$ ethanol for $1 \mathrm{~min}$, followed by $10 \mathrm{~min}$ in $50 \%$ commercial bleach (equivalent to $2.5 \%$ $\mathrm{NaOCl})$ and then washed five times in sterile distilled water. They were sown on $1 / 4$ strength Murashige and Skoog (MS) medium (Murashige and Skoog 1962) supplemented with $1 \%(\mathrm{w} / \mathrm{v})$ sucrose, $0.8 \%(\mathrm{w} / \mathrm{v})$ agar (Phytoagar, Duchefa), $\mathrm{pH} 5.8$, first in the presence of $1,10,100 \mathrm{nM}, 1,10 \mu \mathrm{M}$ 2iP, BAP, TDZ, 5-BDPU or 6-BDPU alone then in the presence of mixtures consisting of $1,10,100 \mathrm{nM} 2 \mathrm{iP}, \mathrm{BAP}$ or TDZ plus $10 \mu \mathrm{M} 5$-BDPU or 6-BDPU. After a cold treatment at $4{ }^{\circ} \mathrm{C}$ for 3 days in the darkness, the plates, containing 25 seeds each, were incubated in a growth chamber at $23 \pm 1{ }^{\circ} \mathrm{C}$ at light intensity of $27 \mu \mathrm{mol} \mathrm{m}{ }^{-2} \mathrm{~s}^{-1}$ under $16 \mathrm{~h}$ photoperiod. Control conditions were performed by seeds grown in hormone free (HF) medium and/or in the presence of the highest volume of DMSO. The effects of the different supplementations on general plant development and leaf shape were evaluated and compared after 2 and 3 weeks, as previously described (Motte et al. 2013). The experiments were repeated twice.

\section{Root elongation inhibition assay}

Arabidopsis thaliana ecotype Columbia (Col-0) seeds surface sterilised as described above were sown on $1 / 4$ strength MS medium supplemented with $1 \%(\mathrm{w} / \mathrm{v})$ sucrose, $0.8 \%$ (w/v) agar (Phytoagar, Duchefa), pH 5.8, in the presence of $10,100 \mathrm{nM}, 1 \mu \mathrm{M} 2 \mathrm{iP}, \mathrm{BAP}, \mathrm{TDZ}$ alone or in the 
simultaneous presence of $10 \mu \mathrm{M} 5$-BDPU or 6-BDPU. After a cold treatment at $4{ }^{\circ} \mathrm{C}$ for 3 days in the darkness, the plates, containing 10 seeds each, were vertically incubated in a growth chamber at $23 \pm 1{ }^{\circ} \mathrm{C}$ at light intensity of $27 \mu \mathrm{mol} \mathrm{m}{ }^{-2} \mathrm{~s}^{-1}$ under $16 \mathrm{~h}$ photoperiod. Control conditions were performed by seeds grown in hormone free (HF) medium and in the presence of $10 \mu \mathrm{M} 5$-BDPU or 6-BDPU alone. Root length was measured after 6 days, as previously described (Motte et al. 2013). The experiments were repeated twice.

\section{Amaranthus seedling test}

The Amaranthus bioassay was performed as previously described (Romanov et al. 2000) with minor modifications. Seeds of Amaranthus caudatus L. were germinated on filter paper moistened with distilled water in the dark at $23{ }^{\circ} \mathrm{C}$ for 4 days. The apical part of the hypocotyls together with the cotyledons (henceworth derooted seedlings) were then cut off and placed in multiwell dishes (12 wells/dish, Costar). Ten derooted seedlings were put in each well containing $600 \mu \mathrm{l}$ phosphate buffer $\left(12 \mathrm{mM} \mathrm{K} \mathrm{HPO}_{4}-\mathrm{NaH}_{2} \mathrm{PO}_{4}, \mathrm{pH}\right.$ 6.4) plus $0.45 \mathrm{mg} / \mathrm{ml}$ L-tyrosine (Sigma), a betacyanin precursor. In a first set of experiments the effects of $10,100 \mathrm{nM}$, 1, $10 \mu \mathrm{M}$ 2iP, BAP, TDZ, 5-BDPU or 6-BDPU alone were analysed. In a second set of experiments mixtures were performed with the 2 lowest concentrations of each cytokinin, i.e. $10,100 \mathrm{nM} 2 \mathrm{iP}$ or BAP or TDZ, plus $10,100 \mathrm{nM}, 1$, $10 \mu \mathrm{M} 5$-BDPU or 6-BDPU, and the corresponding effects were detected. Control conditions were performed by derooted seedlings put in the presence of tyrosine alone and/ or in the presence of the highest DMSO volume. To prevent light induced betacyanin formation all these handlings were done in green dim light. After $20 \mathrm{~h}$ incubation in the dark at $23{ }^{\circ} \mathrm{C}$, the derooted seedlings were collected and placed in cold $0.1 \mathrm{M} \mathrm{HCl}$. Betacyanin was extracted following four cycles of freezing and thawing. The optical density was determined at $540 \mathrm{~nm}$. The experiments were carried out in triplicate, and repeated three times.

\section{Shoot regeneration assay}

Seeds of Lycopersicon esculentum Mill. var. Alice were surface sterilized, sown and germinated as previously described (Ricci et al. 2001b). Twelve cotyledon explants, obtained from 1-week old in vitro cultured seedlings, were plated in each Petri dish containing full strength MS medium supplemented with MS vitamins, 3\% (w/v) sucrose, $0.8 \%$ (w/v) agar (Phytoagar, Duchefa), pH 5.8, in the presence of 1, 5, $10 \mu \mathrm{M} 2 \mathrm{iP}, \mathrm{BAP}$ or TDZ, as adenine- or urea-type cytokinins, or in the presence of $0.1,1,10 \mu \mathrm{M} 5$-BDPU alone, to verify their shoot regeneration capacity by a dose-response curve. In a second set of experiments the tomato cotyledon explants were plated on the same tissue culture medium described above in the presence of the mixtures made by $5 \mu \mathrm{M} 2 \mathrm{iP}$, BAP or TDZ respectively, plus $0.1,1,10 \mu \mathrm{M}$ 5-BDPU. To validate each experiment control condition was performed by cotyledon explants grown in the presence of $1.4 \mu \mathrm{M}$ trans-zeatin riboside plus $20 \mu \mathrm{M}$ BOAA (Ricci et al. 2001b). Petri dishes were incubated at $24 \pm 1{ }^{\circ} \mathrm{C}$ at light intensity of $27 \mu \mathrm{mol} \mathrm{m}{ }^{-2} \mathrm{~s}^{-1}$ under $16 \mathrm{~h}$ photoperiod. After two-week incubation, cotyledon explants were transferred to hormone free (HF) medium and the percentage of the explants forming shoots was checked two weeks later. The experiments were done in triplicate and repeated three times.

\section{Effect on GUS activity in ARR5::GUS transgenic plants}

Arabidopsis thaliana ARR5::GUS transgenic plants in Col-0 background, homozygous for the GUS reporter gene (To et al. 2004), were used in this study. Seeds were surface sterilised in $70 \%$ ethanol for $1 \mathrm{~min}$, followed by $10 \mathrm{~min}$ in $50 \%$ commercial bleach (equivalent to $2.5 \% \mathrm{NaOCl}$ ), washed five times in sterile distilled water, sown on $1 / 4$ strength MS medium supplemented with $1 \%(\mathrm{w} / \mathrm{v}$ ) sucrose, $50 \mu \mathrm{g} / \mathrm{ml}$ kanamycin, $0.8 \%$ (w/v) agar (Phytoagar, Duchefa), pH 5.8 and kept in the dark at $25^{\circ} \mathrm{C}$.

Four-day-old seedlings were transferred to $1 / 2$ strength MS liquid medium plus 1.5\% (w/v) sucrose, alone (hormone free, HF) or supplemented with 1, 10 or $100 \mathrm{nM} 2 \mathrm{iP}, \mathrm{BAP}$, or TDZ alone as exogenous cytokinins; $1,10,100 \mathrm{nM}, 1,10$ or $100 \mu \mathrm{M} 5$-BDPU alone; $2 \mathrm{iP}(1$ or $10 \mathrm{nM})$ in combination with 5 -BDPU $(1,10,100 \mathrm{nM}$ or 1,10 or $100 \mu \mathrm{M})$; BAP (1 or $10 \mathrm{nM})$ in combination with 5-BDPU $(1,10,100 \mathrm{nM}$ or 1,10 or $100 \mu \mathrm{M})$; TDZ (1 or $10 \mathrm{nM}$ ) in combination with 5 -BDPU $(1,10$ or $100 \mathrm{nM}$ or 1,10 or $100 \mu \mathrm{M})$. Ten seedlings were used in each treatment. The HF condition was assumed as internal control to validate the experimental procedure, while the supplementation of $2 \mathrm{iP}, \mathrm{BAP}$ and/or TDZ was assumed as control either of 5-BDPU or of each combination treatment, respectively. After $5 \mathrm{~h}$ incubation in multiwell dishes kept in a growth chamber at $24 \pm 1{ }^{\circ} \mathrm{C}$ with a light intensity of $27 \mu \mathrm{mol} \mathrm{m} \mathrm{m}^{-2} \mathrm{~s}^{-1}$, the seedlings were vacuum infiltrated for $10 \mathrm{~min}$ and then submerged in X-Gluc solution containing $100 \mathrm{mM}$ sodium phosphate buffer $(\mathrm{pH}$ 7.0), $1 \mathrm{mM}$ 5-bromo-4-chloro-3-indolyl-b-D-glucuronide, $10 \mathrm{mM}$ EDTA, $1 \mathrm{mM} \mathrm{K} 3 / \mathrm{K} 4(\mathrm{FeCN})_{6}, 0.1 \%$ (v/v) Triton $\mathrm{X}-100,1 \%(\mathrm{v} / \mathrm{v}) \mathrm{N}, \mathrm{N}$-dimethylformamide (Bai and Demason 2008, with minor modifications. Incubation was carried out for $5 \mathrm{~h}$ at $37^{\circ} \mathrm{C}$. The seedlings were then washed three times in distilled water to remove excess substrate, cleared in freshly made ethanol:acetic acid (6:1, v/v) solution overnight at $4{ }^{\circ} \mathrm{C}$, washed twice in $96 \%(\mathrm{v} / \mathrm{v})$ ethanol and stored in $70 \%$ $(\mathrm{v} / \mathrm{v})$ ethanol (Mattsson et al. 2003, with minor modifications). Seedlings were observed for each treatment with a stereomicroscope with Nikon DSFil digital camera (whole 
seedling) and with a conventional light microscope with a Leica DC 100 digital camera (close-up views). Experiments were repeated three times.

\section{Heterologous bacterial assay}

Escherichia coli strain KMI001, harbouring vector pINIII-AHK4 expressing the Arabidopsis cytokinin receptor CRE1/AHK4, that is capable of signalling the downstream YojN $\rightarrow R \operatorname{Rcs} \rightarrow$ cps: :lacZ pathway in response to external cytokinins, was used in the experiments (Suzuki et al. 2001; Yamada et al. 2001). Therefore, the activation of the signalling pathway can be easily monitored by measuring $\beta$-galactosidase activity of $E$. coli cells. Bacterial strains were kindly provided by dr. T. Mizuno (Nagoya, Japan). Bacteria were grown in Luria-Bertani (LB) medium (Sambrook et al. 1989) at $37^{\circ} \mathrm{C}$ with ampicillin $(50 \mu \mathrm{g} / \mathrm{ml})$ with extensive shaking. Culture density was controlled by measuring the absorption at $600 \mathrm{~nm}\left(\mathrm{OD}_{600}\right)$. A homogenous bacterial suspension $\left(\mathrm{OD}_{600}\right.$ between 0.04 and 0.4$)$ was aliquoted in multiwell dishes supplemented with $0.1,1,10 \mu \mathrm{M}$ 2iP, BAP or TDZ as adenine- or urea-type cytokinins, or with $0.1,1,10 \mu \mathrm{M}$ 5-BDPU or 6-BDPU alone, or with the mixtures made by a single $(1 \mu \mathrm{M})$ concentration of $2 \mathrm{iP}$, BAP or TDZ plus $0.1,1,10 \mu \mathrm{M} 5$-BDPU or 6-BDPU. Bacteria grown in the presence of the relative volumes of DMSO were used as control. After $40 \mathrm{~h}$ incubation at $25{ }^{\circ} \mathrm{C}$ in the dark, the $\beta$-galactosidase activity was detected as described by Zhang and Bremer (Zhang and Bremer 1995) with minor modifications. Twenty $\mu \mathrm{l}$ samples of cultures were mixed into $80 \mu \mathrm{l}$ of permeabilization solution $(0.8 \mathrm{mg} / \mathrm{ml}$ hexadecyltrimethylammonium bromide, $0.4 \mathrm{mg} / \mathrm{ml}$ sodium deoxycholate, $100 \mathrm{mM} \mathrm{Na}_{2} \mathrm{HPO}_{4}, 20 \mathrm{mM} \mathrm{KCl}, 2 \mathrm{mM}$ $\mathrm{MgSO}_{4}, 5.4 \mu \mathrm{l} / \mathrm{ml} \beta$-mercaptoethanol). This mixture was kept at $30{ }^{\circ} \mathrm{C}$ for $1.30 \mathrm{~h}$, then $600 \mu \mathrm{l}$ of $30{ }^{\circ} \mathrm{C}$ prewarmed substrate solution $\left(60 \mathrm{mM} \mathrm{Na}{ }_{2} \mathrm{HPO}_{4}, 40 \mathrm{mM} \mathrm{NaH} \mathrm{PO}_{4}\right.$, $1 \mathrm{mg} / \mathrm{ml} o$-nitrophenyl- $\beta$-D-galactopyranoside, $2.7 \mu \mathrm{l} / \mathrm{ml}$ $\beta$-mercaptoethanol) were added to initiate the reaction. After $2 \mathrm{~h}$ at $30{ }^{\circ} \mathrm{C}$, reactions were stopped by the addition of $700 \mu \mathrm{l}$ of $1 \mathrm{M} \mathrm{Na}_{2} \mathrm{CO}_{3}$ and the absorption at $420 \mathrm{~nm}$ was recorded for each sample. Enzyme activities were expressed as Miller units (Miller 1972) by the formula $1000 \times\left[\mathrm{OD}_{420} /\right.$ $\left.\left(\mathrm{OD}_{600} \times 20 \mu \mathrm{l} \times 120 \mathrm{~min}\right)\right]$. Experiments were carried out in triplicate and repeated twice.

\section{Live-cell cytokinin-binding assay}

The assay was performed as described by Nisler et al. (2010).

\section{CKX inhibition measurements}

ZmCKX1 was expressed in yeast Yarrowia lipolytica then purified and the inhibition assay was performed according to a published protocol (Kopečný et al. 2005), using 2,6-dichlorophenol indophenol (DCPIP) as an electron acceptor. Compounds were tested with two replicates and the entire test was repeated at least twice. Gene 5 software was used to calculate the residual CKX activity for each compound and concentration. $\mathrm{IC}_{50}$ values for each compound were determined in Origin Pro software.

\section{Statistical analyses}

Root elongation inhibition assay Analysis of variance (ANOVA) was performed and the significantly different values among the mean root lengths were identified by Fisher's LSD test $(p \leq 0.05)$, using the statistical software package SPSS 26.

Amaranthus seedling test Differences among the mean values of betacyanin accumulation were examined with nonparametric Kruskal-Wallis test $(p \leq 0.05)$, using the statistical software package SPSS 26.

Shoot regeneration assay Differences among the percentages of cotyledon explants forming shoots were examined with asymptotic Wilcoxon Mann-Whitney rank sum test ( $p \leq 0.05$ ) using R statistics package (R Core Team 2013).

Heterologous bacterial assay All data were first submitted to logarithmic or Box-Cox power transformation (Box and Cox 1964). Statistical analysis was performed by analysis of variance (ANOVA) and the significantly different values $(p \leq 0.01)$ were identified by the Tukey's HSD test. Before the ANOVA the hypothesis of homoscedasticity was tested using the Fligner-Killeen test. The statistical analyses were performed by R statistics package (R Core Team 2013).

\section{Molecular docking simulations}

\section{CRE1/AHK4 receptor}

The crystal structure of the Arabidopsis histidine kinase 4 sensor domain (CRE1/AHK4), containing the cytokinin binding site, was retrieved from the Protein Data Bank (PDB) (Berman et al. 2000) in the dimeric form complexed with $\mathrm{N}^{6}$-(2-isopentenyl)adenine (2iP) [PDB ID: 3T4J (Hothorn et al. 2011)], and used after deletion of all ligands and water molecules (except for the simulations performed with two conserved waters, see below). The crystal structures of all the available complexes of CRE1/ AHK4 with different natural and synthetic cytokinins were 
considered. They all have the same resolution; in addition, all the residues of the binding site are perfectly superimposable, meaning that the differences between the compounds seem to have minimal effects on the ligand neighborhood. This observation not only minimizes the induced-fit effects, but also makes the choice of the compound for the reference docking simulation, not critical. The CRE1/AHK4-2iP complex was chosen on the basis of its known high affinity (Romanov et al. 2006) and 2iP relevance in our experimental results. The structure of $2 \mathrm{iP}$ extracted from the crystal was re-docked into the binding site as a reference test for the docking parameters. In the chosen enzyme structure 3T4J, Met256 is the only residue of the binding pocket that presents two different orientations, with occupancy of 0.26 and 0.74 . Therefore, in the first docking simulation with $2 \mathrm{iP}$, both of them were tested, seeming not to have any influence on the ligand binding mode. The residue orientation with higher occupancy was thus definitely used for further investigation.

Receptor hydrogens were added by means of MolProbity software (Davis et al. 2007), that checks also for the flip of Asn, Gln and His sidechains. His were kept in the neutral form. Gasteiger partial charges (Gasteiger and Marsili 1980) were added.

Both 2iP and BDPUs binding mode was tested also in the presence of the two conserved water molecules that make bridges between the protein and the nitrogen atoms of adenine ring (Hothorn et al. 2011), keeping them inside the receptor structure. Their hydrogen atoms and Gasteiger partial charges were added with the Chimera software (Pettersen et al. 2004).

For the docking of $2 \mathrm{iP}$, the grid maps were centered on the cytokinin binding site of chain A, with a box size of $86 \times 88 \times 88$ points, $0.375 \AA$ A spaced.

For the docking of BDPUs, two grids were used. The first grid was centered on the cytokinin binding site of chain A, with a box size of $86 \times 88 \times 88$ points, $0.375 \AA$ spaced. A second bigger grid, comprehending the whole dimer surface, was built, with box dimensions of $106 \times 90 \times 102$ points, with a spacing of $0.7 \AA$. Then, around the new prevalent ligand position found, the orientation was refined with a smaller grid $(84 \times 84 \times 88)$ with a spacing of $0.375 \AA$.

\section{CKX enzyme}

The crystal structure of the maize cytokinin oxidase/dehydrogenase type 1 ( $\mathrm{ZmCKX} 1$ ) was retrieved from the Protein Data Bank (PDB) (Berman et al. 2000) in complex with N-phenyl-N'-(2-chloro-4-pyridyl)urea (CPPU) inhibitor [PDB ID: 2QKN (Kopečný et al. 2010)]. The ZmCKX1 $2 \mathrm{QKN}$ structure was chosen for the docking because it was of the same type of the one used for the inhibition experiments, and because available in complex with a urea-type inhibitor structurally similar to BDPUs, that we used for reference and comparison.

The only available crystal structure of the Arabidopsis cytokinin oxidase/dehydrogenase was type 7 (AtCKX7) and was again retrieved from PDB [PDB ID: 2EXR (Bae et al. 2008)].

The CKX structures were prepared for docking after deletion of all water molecules and ligands, with the exception of the flavin-adenine dinucleotide (FAD) because of its implication in the inhibitor binding.

Receptor hydrogens were added by means of MolProbity software, checking also for the flip of Asn, Gln and His sidechains; His were kept in the neutral form and Gasteiger partial charges (Gasteiger and Marsili 1980) were added.

The structure of CPPU extracted from the crystal was re-docked into the binding site to check the docking parameters and the binding energy value, keeping the two active torsions (i.e. those around the bonds connecting the urea group and the rings) free to rotate.

The grid maps were centered in the binding cavity, with dimensions of $54 \times 64 \times 56$ points and a spacing of $0.375 \AA$.

\section{BDPU ligands}

The structure of 5-BDPU and 6-BDPU used for the docking simulations were built by means of the PRODRG server (van Aalten et al. 1996) and minimized by the Avogadro program (Hanwell et al. 2012) with the MMFF94 force field (Wang et al. 2006). Gasteiger partial charges were added to the ligands. The only two 5-BDPU and 6-BDPU torsions that were able to rotate (i.e. around the bonds between the $\mathrm{N}$ atoms and the aromatic substituents) were kept free.

\section{Docking simulation parameters}

The docking simulations were performed with the Autodock 4.2 software package, with the aid of the AutoDockTools (ADT) interface (Morris et al. 2009).

For the docking calculations, the Lamarckian Genetic Algorithm (Morris et al. 1998) was used, performing 1000 runs, each with $10^{7}$ energy evaluations, assuring in such a way the convergence of the docking. For each run, 250 individuals in the initial population, and 27,000 generations were set. A conformational cluster analysis was carried out on the docked conformations, to determine similarity of the ligand poses within a rmsd value of $2 \AA$, reporting the clusters ranked by increasing energy, by the lowest energy in each cluster (Morris et al. 1998). All the clusters were analyzed, in particular the ones with the lowest energy and the most populated (i.e. the statistically most probable binding mode).

Structural analysis of the binding modes was made using ADT, VMD (Humphrey et al. 1996) and Swiss-PdbViewer 
(Guex and Peitsch 1997) software and the web tool for macromolecular visualization FirstGlance in Jmol (The Jmol Team 2007) (http://bioinformatics.org/firstglance/fgij/index. htm).

The cation- $\pi$ interactions with BDPUs were assessed using the criterion of the web-based software "First Glance in Jmol" (Herráez 2006), that is a distance less than $6.0 \AA$ between the cation and three alternate carbons in the aromatic ring.

\section{Results}

\section{Cytokinin bioassays}

\section{Plant development}

Cytokinin-treated plants had a stunted appearance, anthocyanin accumulation was clearly visible, leaves frequently showed jagged margins and sometimes they were completely malformed, root growth was strongly reduced. All these cytokinin responses became more evident as the concentrations and/or the length of the supplementation period increased, as expected (Figs. 2 and S1). These alterations were visible at different stages even when plants were cultured in the presence of the mixtures, depending on the type of cytokinin. More precisely, when low concentrations of 2iP were added to 5-BDPU or 6-BDPU the cytokinin-driven effects were extremely mild. Otherwise, when 5-BDPU or 6-BDPU were supplemented in the simultaneous presence of low concentrations of BAP these effects were even more visible than the ones obtained in the presence of the same concentration of BAP alone. When 5-BDPU or 6-BDPU were supplemented in the simultaneous presence of low concentrations of TDZ the effects were particularly severe (Fig. 3). None of these alterations in the general development was clearly visible when plants were grown in the presence of the different concentrations of 5-BDPU or 6-BDPU alone throughout the entire supplementation period, as they appeared similar to that grown in control conditions (Figs. 2 and S1).

\section{Root elongation inhibition assay}

The concentration-dependent inhibition effect of cytokinins on root elongation was detected in the presence of the different concentrations of 2iP, BAP and TDZ, as expected (Fig. 4a-c), neither 5-BDPU nor 6-BDPU affected the root elongation compared to the hormone free condition (Fig. 4d). Interestingly, the inhibition of root elongation was significantly enhanced when Arabidopsis plants were cultured in the simultaneous presence of the different concentrations of $2 \mathrm{iP}$ and $10 \mu \mathrm{M} 5$-BDPU or 6-BDPU,

\section{2 weeks $\quad 3$ weeks}

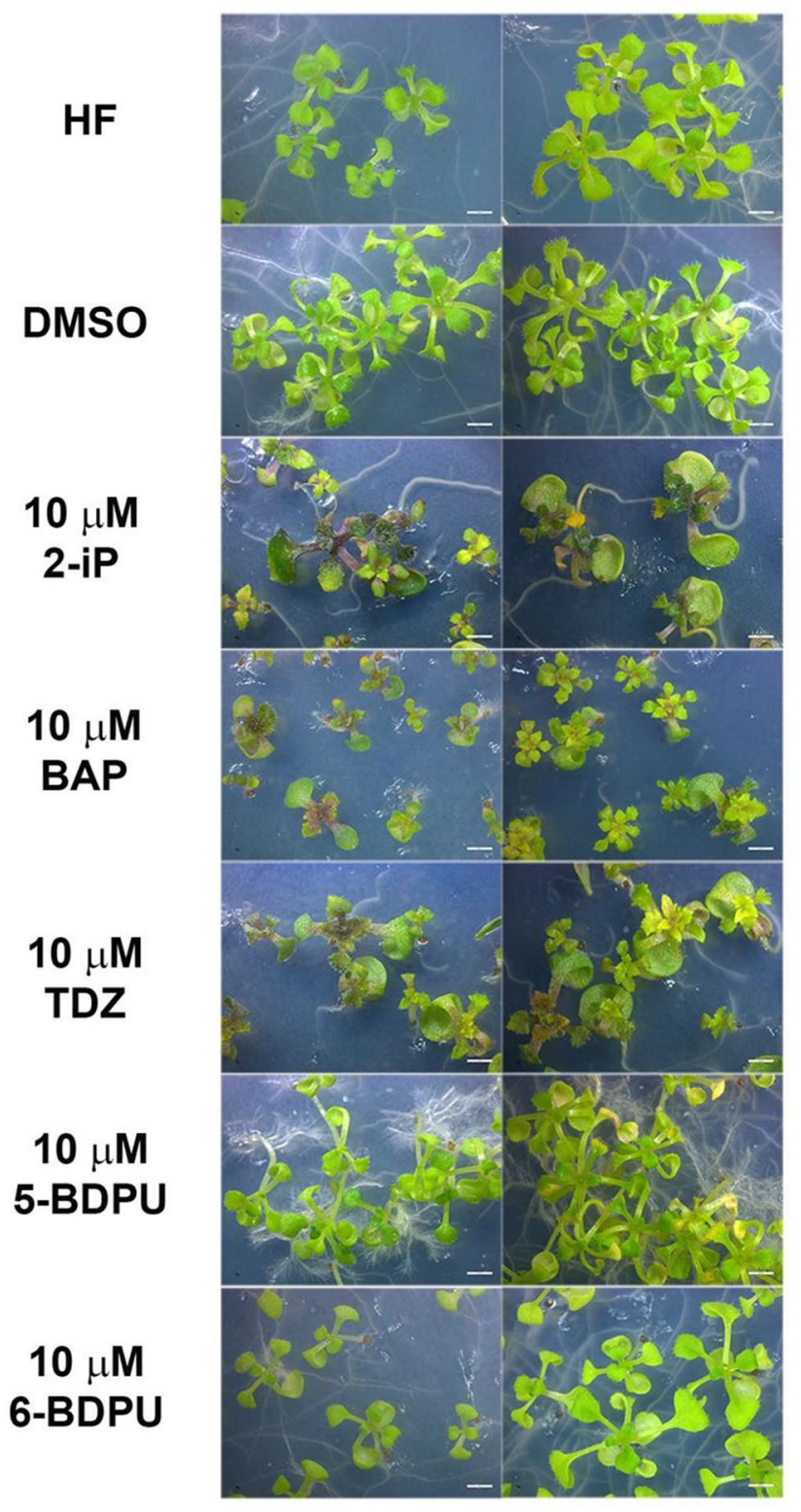

Fig. 2 Representative morphological appearance of Arabidopsis Col-0 plants grown for 2 and 3 weeks in the continuous presence of $10 \mu \mathrm{M}$ 2iP, BAP, TDZ, 5-BDPU, 6-BDPU or in their absence (HF and DMSO). Scale bars $=1 \mathrm{~mm}$. For the effects of other concentrations see Fig. S1

compared with the inhibition caused by the corresponding 2iP supplementation alone (Fig. 4a). Similar results were obtained in the presence of BAP, as cytokinin (Fig. 4b). When TDZ was present in the culture medium the inhibition of root elongation was significantly enhanced by the mixtures $100 \mathrm{nM}$ TDZ plus $10 \mu \mathrm{M}$ 6-BDPU and $1 \mu \mathrm{M}$ TDZ plus $10 \mu \mathrm{M} 5$-BDPU or $10 \mu \mathrm{M} 6-\mathrm{BDPU}$, compared with the 


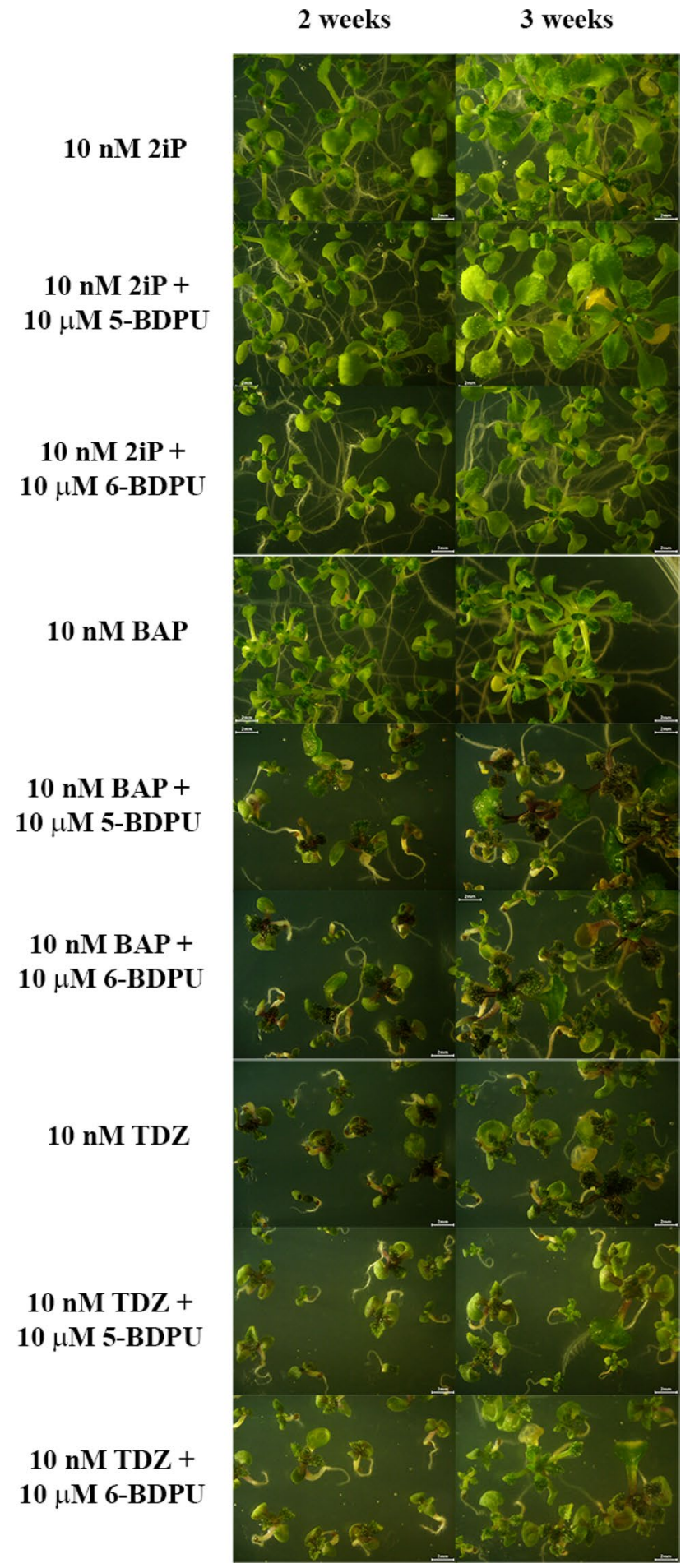

Fig. 3 Representative morphological appearance of Arabidopsis Col-0 plants grown for 2 and 3 weeks in the continuous presence of $10 \mathrm{nM} 2 \mathrm{iP}, \mathrm{BAP}, \mathrm{TDZ}$ alone or in mixtures consisting of $10 \mathrm{nM} 2 \mathrm{iP}$, BAP, TDZ plus $10 \mu \mathrm{M} 5$-BDPU or 6-BDPU respectively
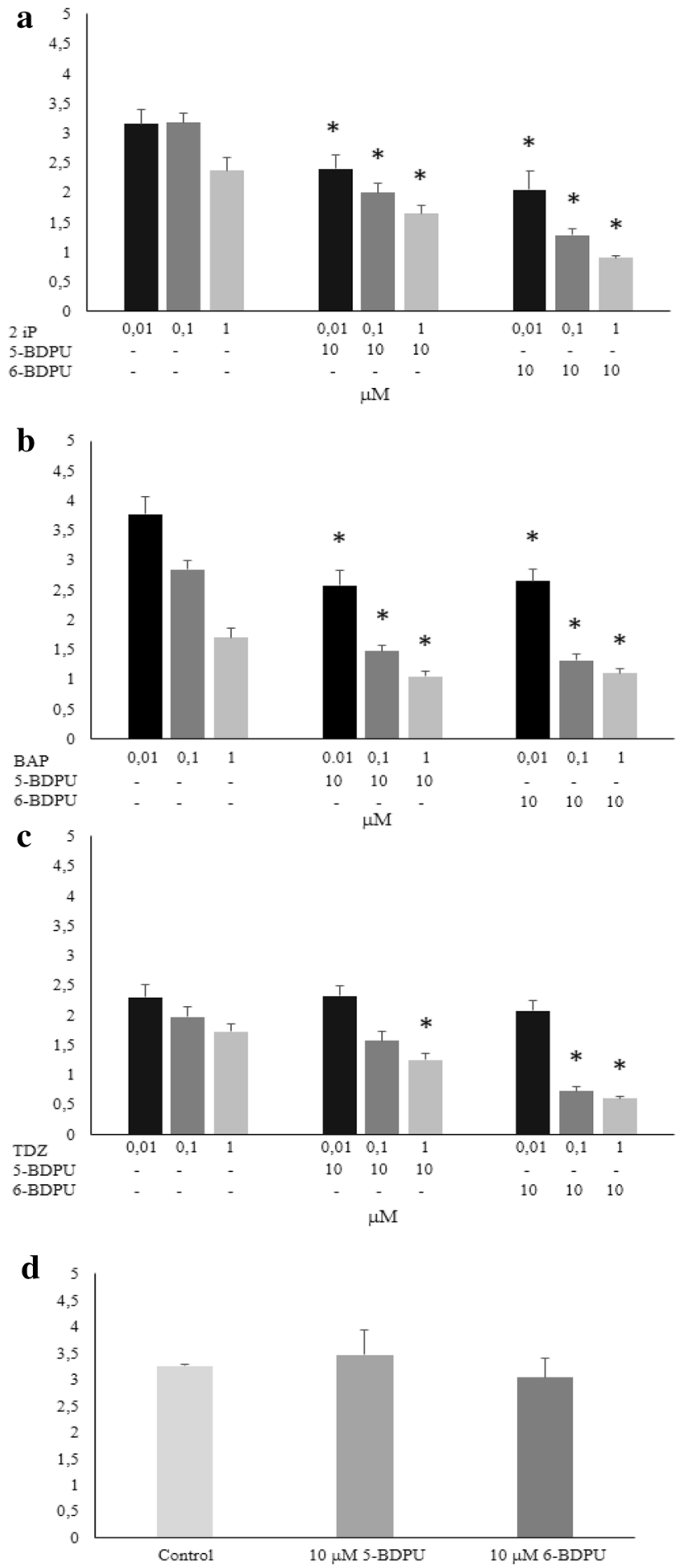

Fig. 4 Effects of $10 \mu \mathrm{M} 5$-BDPU or 6-BDPU on the mean root length of Arabidopsis Col-0 plants in the simultaneous presence of different concentrations of a $2 \mathrm{iP}, \mathbf{b} \mathrm{BAP}, \mathbf{c} \mathrm{TDZ}$; $\mathbf{d}$ effects of the absence (HF) or of the presence of $10 \mu \mathrm{M} 5$-BDPU or 6-BDPU alone. Columns labelled with asterisks are significantly different (Fisher's LSD test, $p \leq 0.05$ ) 
inhibition caused by the corresponding TDZ supplementation alone (Fig. 4c).

\section{Amaranthus seedling test}

The concentration-dependent effect of cytokinins on accumulation of betacyanin was detected in the presence of the different concentrations of 2iP, BAP and TDZ, as expected, while the same concentrations of 5-BDPU or 6-BDPU alone

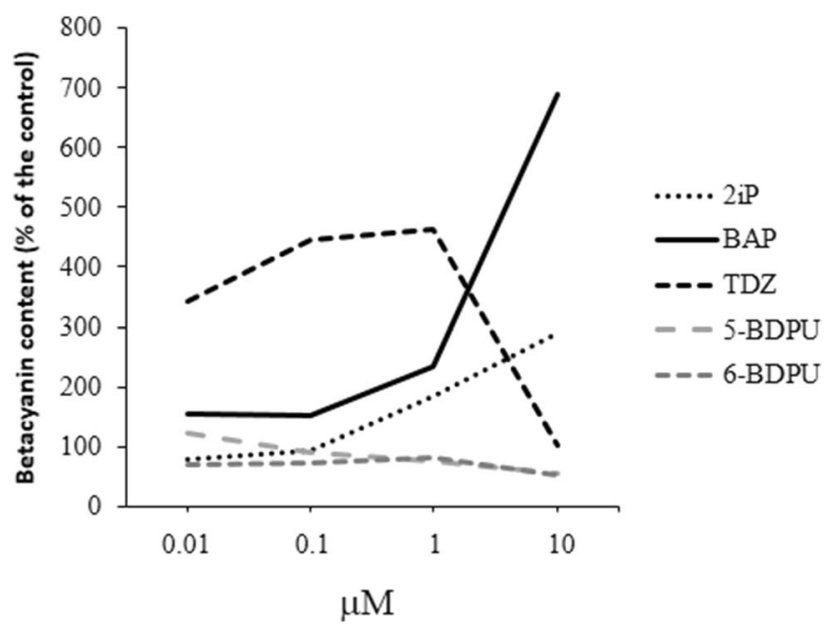

Fig. 5 Effects of different concentrations of 2iP, BAP, TDZ, 5-BDPU or 6-BDPU in the betacyanin accumulation in derooted seedlings of Amaranthus. Results are expressed as optical density at $540 \mathrm{~nm}$. For the effects of the mixtures see Fig. S2 were completely ineffective (Fig. 5). In the second set of experiments the addition of increasing concentrations of 5 -BDPU or 6-BDPU to 10 or $100 \mathrm{nM} 2 \mathrm{iP}, \mathrm{BAP}$ or TDZ as fixed concentrations did not affect this physiological process. In fact, the betacyanin accumulation detected in the presence of the mixtures did not significantly differ from that obtained by each corresponding $2 \mathrm{iP}$, BAP or TDZ supplementation alone (Fig. S2).

Tyrosine by itself and DMSO had no effect on the reaction studied (data not shown).

\section{Shoot regeneration assay}

When different concentrations of 5-BDPU were supplemented alone to tomato cotyledon explants they were ineffective (data not shown). On the contrary, when 1, 5, $10 \mu \mathrm{M}$ 2iP, BAP or TDZ respectively were supplemented alone to tomato cotyledon explants they were able to induce shoot regeneration, each of them to its own extent in a dosedependent manner. Thus, to verify if BDPUs were able to enhance the cytokinin-dependent shoot regeneration process, tomato cotyledon explants were maintained in the presence of the mixtures made by $5 \mu \mathrm{M} 2 \mathrm{iP}$, BAP, TDZ, respectively, as intermediate concentration value, plus $0.1,1,10 \mu \mathrm{M}$ 5-BDPU. Only in the simultaneous presence of $5 \mu \mathrm{M} 2 \mathrm{iP}$ and $10 \mu \mathrm{M} 5$-BDPU the percentage of explants forming shoots was enhanced, as it was significantly higher than that of the same 2iP concentration alone (Fig. 6). No significant enhancement in the percentage of the shoot regenerating
Fig. 6 Effect of different concentrations of 5-BDPU on shoot regeneration of tomato cotyledons in the simultaneous presence of $5 \mu \mathrm{M} 2 \mathrm{iP}$. Results are expressed as percentage of explants forming shoots. Columns labelled with different letters are significantly different (Wilcoxon Mann-Whitney rank sum test, $p \leq 0.05$ )

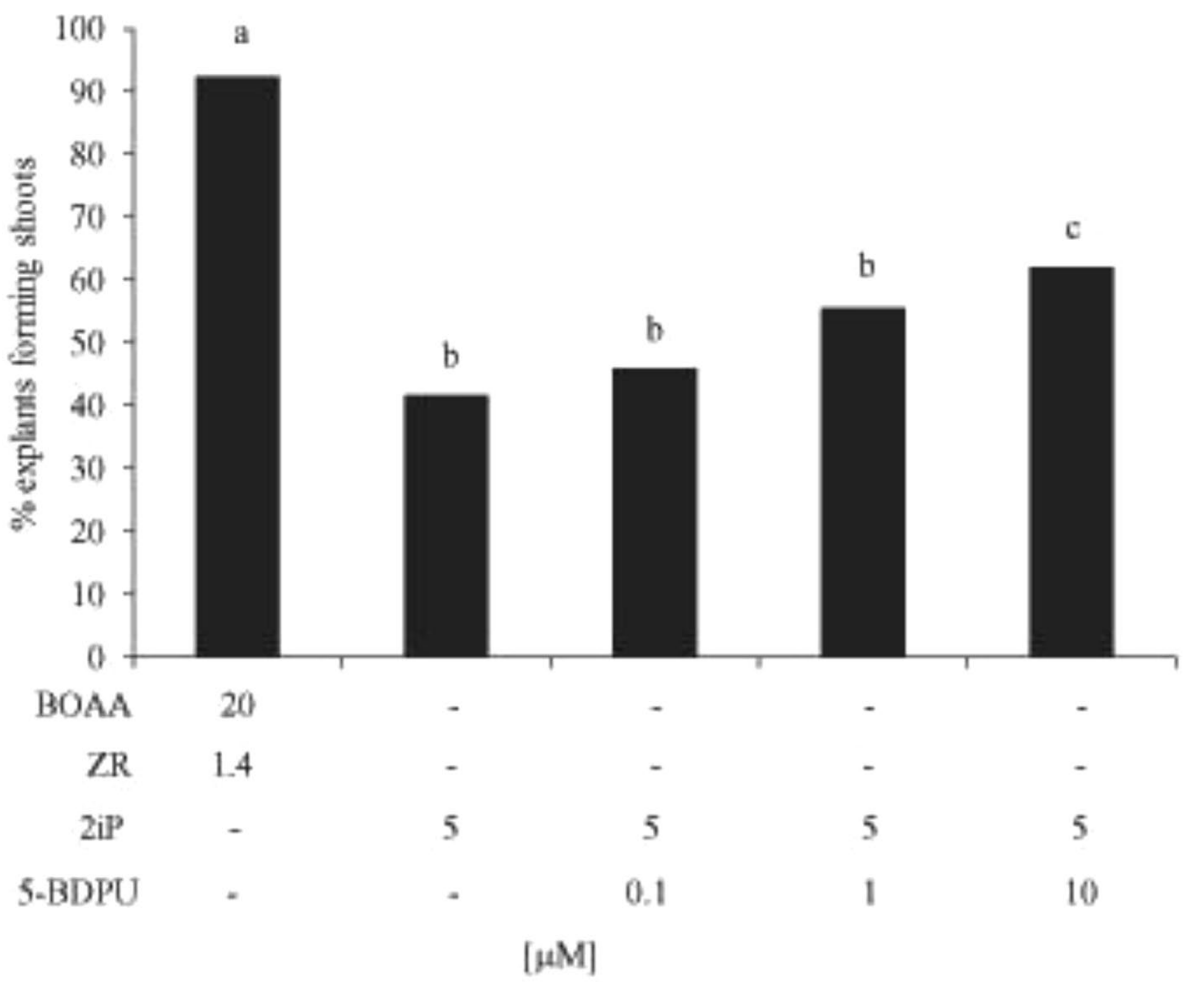


explants was detected when cotyledon explants were cultured in the presence of the mixtures made by $5 \mu \mathrm{M}$ BAP or TDZ plus $0.1,1,10 \mu \mathrm{M}$ 5-BDPU (data not shown).

\section{Effect on GUS activity in ARR5::GUS transgenic plants}

The results of the series of the bioassays performed and described above suggested that, despite the fact that 5-BDPU or 6-BDPU are not showing cytokinin-like activity, most likely they interact with the cytokinin status of plants. To investigate this we first analysed whether 5-BDPU interacts with cytokinins in planta, using the reporter activity in Arabidopsis thaliana ARR $5:: G U S$ transgenic plants, in response to different types of supplementation. GUS expression was found in the root and shoot meristem regions at day four after sowing when seedlings were cultured in the absence of exogenous cytokinins (hormone free condition), as already described (D'Agostino et al. 2000; To et al. 2004) (data not shown). No considerable changes in this spatial pattern were detected when seedlings were cultured in the presence of the different 5-BDPU concentrations (data not shown).

Interestingly, GUS expression was strengthened when 5-BDPU was supplemented to seedlings simultaneously with $2 \mathrm{iP}$, as natural adenine-type cytokinin. In fact, GUS activity was clearly induced at root tips and in the vasculature of primary root in the presence of exogenous $1 \mathrm{nM}$ $2 \mathrm{iP}$, while a stronger staining was visible when different 5-BDPU concentrations were also present, as representative ones $100 \mathrm{nM}$ and $100 \mu \mathrm{M}$ 5-BDPU (Fig. 7a). When ten-fold higher $2 \mathrm{iP}$ concentration was supplemented to the seedlings, staining was clearly detectable at root tips, while the signal became darker and even more diffused in all the tissues of the primary root in the presence of $10 \mathrm{nM} 2 \mathrm{iP}$ plus $100 \mathrm{nM}$ or $100 \mu \mathrm{M} 5$-BDPU (Fig. 7b). On the contrary, no evident differences in intensity and/or diffusion of GUS expression were visible at the primary root-hypocotyl junctions (Fig. 7a, b).

Once again, when seedlings were supplemented with $1 \mathrm{nM}$ or $10 \mathrm{nM} \mathrm{TDZ}$, as synthetic urea-type cytokinin, the signal was visible at root tips and in the vasculature of primary root in a concentration dependent manner. The signal became partially darker or more diffused in the primary root when $100 \mathrm{nM}$ or $100 \mu \mathrm{M} 5$-BDPU were added to $10 \mathrm{nM}$ TDZ concentrations. No evident differences in intensity and/ or diffusion of GUS expression were visible at the primary root-hypocotyl junctions (Fig. 7c, d).

BAP induced very high GUS expression if compared with the results obtained in the presence of exogenously added $2 \mathrm{iP}$ or TDZ. Even in the presence of the low concentrations of BAP (1 or $10 \mathrm{nM}$ ) GUS staining was so dark and widespread in the primary root tissues that it was impossible to observe an enhancement in its intensity when 5-BDPU was simultaneously supplemented to seedlings (data not shown).

\section{Interaction of BDPUs with the cytokinin receptor CRE1/ AHK4}

To verify if 5-BDPU and/or 6-BDPU could interact with the cytokinin signalling pathway, we analysed their capacity to interact with the Arabidopsis cytokinin receptor CRE1/AHK4 in the heterologous bacterial assay. 5-BDPU and 6-BDPU were unable to activate the receptor, at each concentration $(0.1,1$ and $10 \mu \mathrm{M})$, confirming that BDPUs do not show any cytokinin-like activity per se. Otherwise, 2iP, BAP and TDZ activated the CRE1/AHK4-mediated signalling pathway to a different extent depending on the type of the molecule and on its concentration, as expected (Fig. 8). This finding was further confirmed by studying of the direct interaction of the BDPUs with CRE1/AHK4 in a live-cell hormone-binding assay (Romanov et al. 2005). Both BDPUs failed to block binding of $3 \mathrm{nM} 2-[3 \mathrm{H}] \mathrm{tZ}$ to the CRE1/AHK4 including in the more than 6.500 higher concentration, confirming that BDPUs have no affinity to the cytokinin-binding site of CRE1/AHK4 (Fig. 9).

Intriguingly, in the simultaneous presence of $1 \mu \mathrm{M} 2 \mathrm{iP}$, BAP and/or TDZ plus either 5-BDPU or 6-BDPU supplemented at different concentrations, the receptor activation was significantly greater than that obtained in the presence of the same concentration of each cytokinin alone (Fig. 8A, $\mathrm{C}, \mathrm{E}$ and B, D, F, respectively). Besides, perhaps as a result of the fixed cytokinin concentration, the activation of the receptor by these mixtures was independent of the 5-BDPU or 6-BDPU concentrations. Interestingly, as shown in Fig. 8A and B, only in the simultaneous presence of $1 \mu \mathrm{M}$ $2 \mathrm{iP}$ plus either 5-BDPU or 6-BDPU, the $\beta$-galactosidase activity was significantly higher even than that measured in the presence of $10 \mu \mathrm{M} 2 \mathrm{iP}$ alone, i.e. a cytokinin concentration tenfold higher than that used in the mixture. No activation of the receptor was detected in the presence of DMSO, as control solvent.

\section{Interaction of BDPUs with ZmCKX1 enzyme}

Due to the fact that the BDPUs are structurally similar to the previously described inhibitors of CKX derived from urea, we further tested the possibility that BDPUs can interact with cytokinin metabolism through interaction with CKX. Hence, we tested the ability of the two derivatives to inhibit the activity of maize $\mathrm{ZmCKX} 1$ in vitro. IC50 values were determined using a saturating concentration of the substrate $2 \mathrm{iP}(10 \mu \mathrm{M})$, using DCPIP de-colorization assay. Both compounds were able to inhibit $\mathrm{ZmCKX1}$ activity, reaching $\mathrm{IC}_{50}$ values of $52 \mu \mathrm{M}$ and $15 \mu \mathrm{M}$ in the case of 5-BDPU and 6-BDPU, respectively (Fig. 10). 
Fig. 7 Histochemical localization of GUS activity. A-D show the effects of the different treatments on ARR $5:: G U S$ expression in the primary roothypocotyl junctions and in the root tips (from the top to the bottom of the panels). Close-up views of the representative phenotypes are shown $\mathbf{a}$

$1 \mathrm{nM} 2 \mathrm{iP}+$

$1 \mathrm{nM} 2 \mathrm{iP}+$ $100 \mathrm{nM}$ 5-BDPU

$100 \mu \mathrm{M}$ 5-BDPU

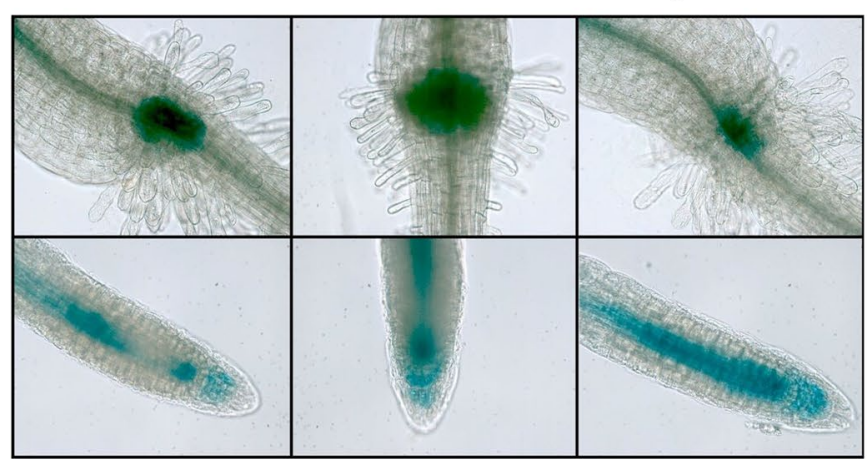

b
10 nM 2iP
$10 \mathrm{nM} 2 \mathrm{iP}+$
$10 \mathrm{nM} 2 \mathrm{iP}+$ $100 \mathrm{nM}$ 5-BDPU
$100 \mu \mathrm{M}$ 5-BDPU

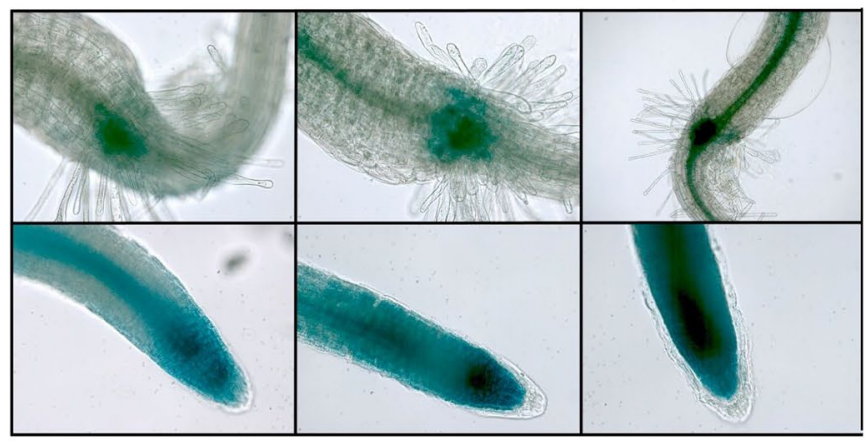

c

1 nM TDZ

1 nM TDZ + 100 nM 5-BDPU

$1 \mathrm{nM}$ TDZ + $100 \mu \mathrm{M}$ 5-BDPU

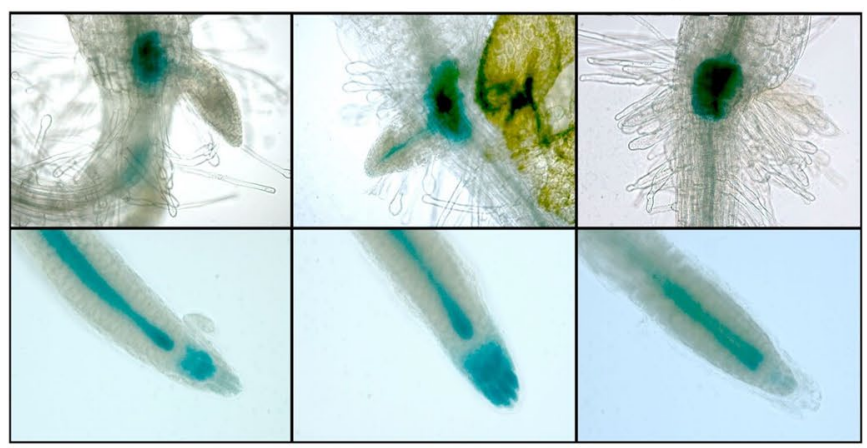

d

$10 \mathrm{nM} T D Z$

$10 \mathrm{nM}$ TDZ + 100 nM 5-BDPU

$10 \mathrm{nM}$ TDZ + $100 \mu \mathrm{M}$ 5-BDPU

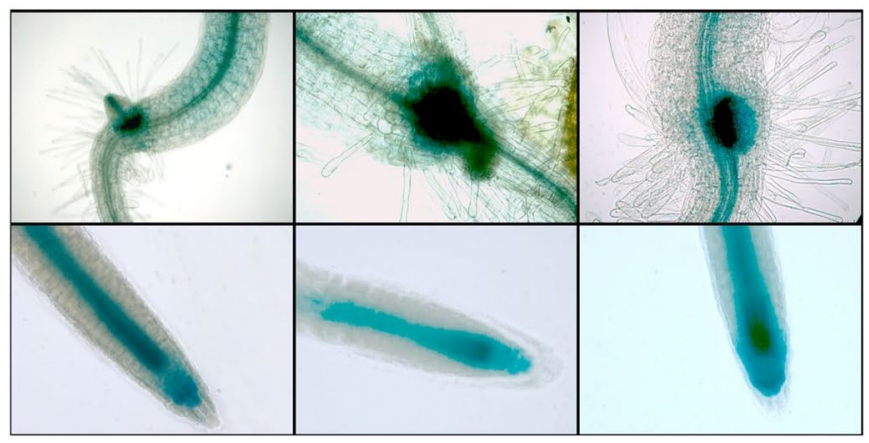


$\mathbf{a}$

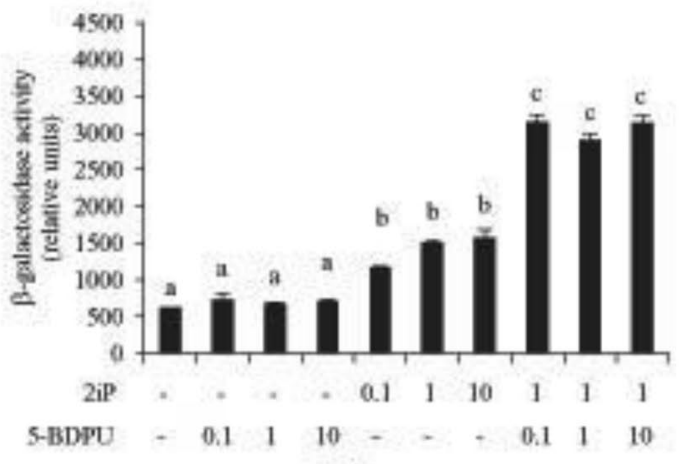

[pM]

c

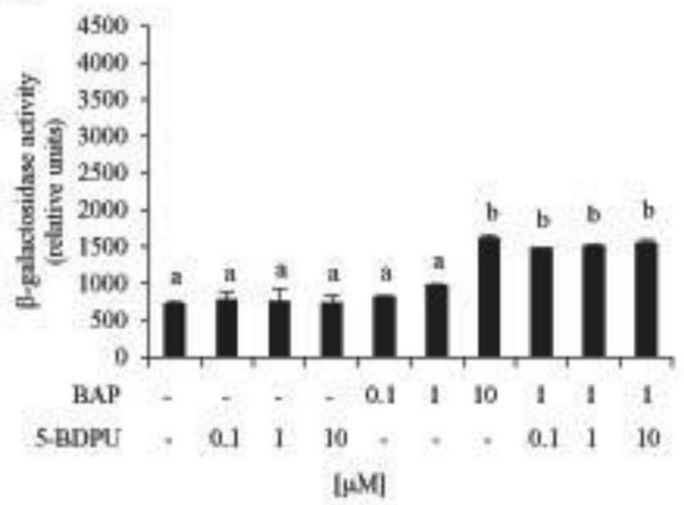

e

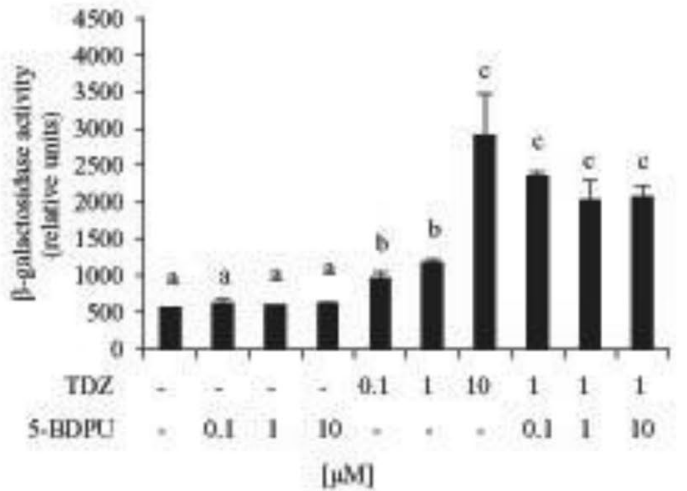

Fig. 8 Activation of cytokinin receptor CRE1/AHK4. a, b show the effect of the different concentrations of 2iP, 5-BDPU, 6-BDPU alone and of the mixtures (2iP plus 5-BDPU, 2iP plus 6-BDPU); $\mathbf{c}, \mathbf{d}$ show the effect of the different concentrations of BAP, 5-BDPU, 6-BDPU alone and of the mixtures (BAP plus 5-BDPU, BAP plus 6-BDPU); e, $\mathbf{f}$ show the effect of the different concentrations of TDZ, 5-BDPU, b

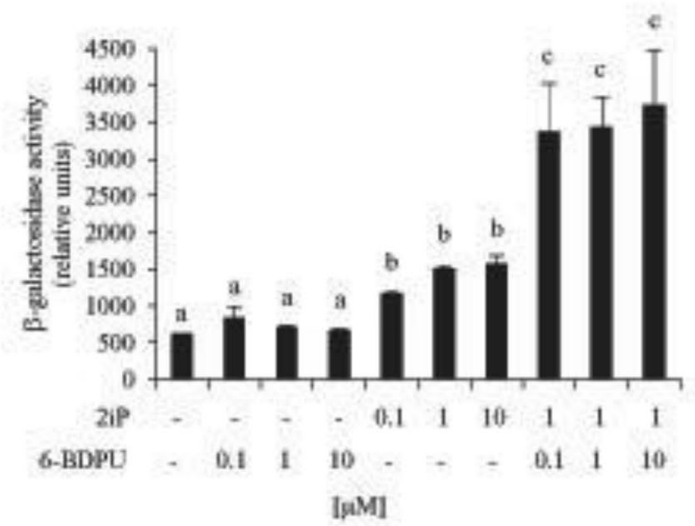

d

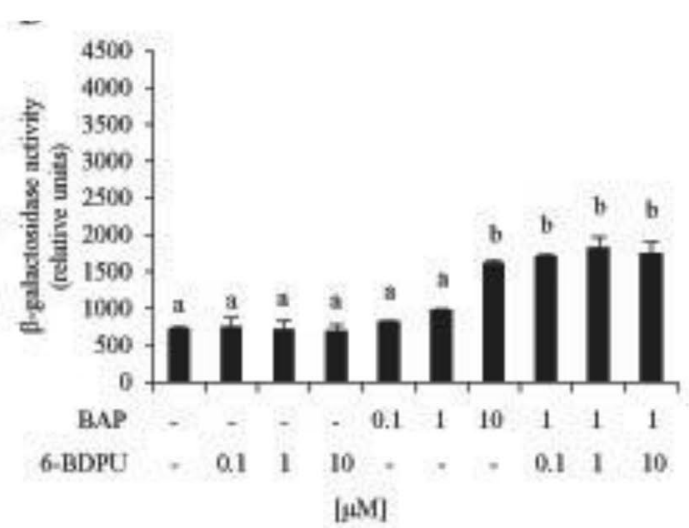

f

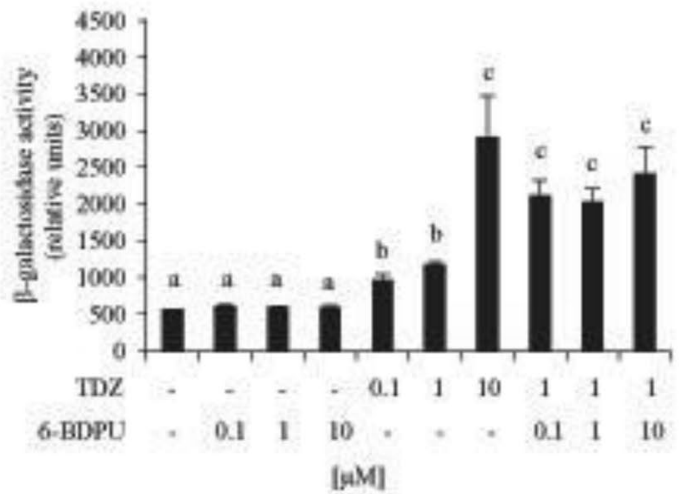

6-BDPU alone and of the mixtures (TDZ plus 5-BDPU, 2iP plus 6-BDPU). $\beta$-Galactosidase activity is expressed as Miller units by the formula $\times 1000\left[\mathrm{OD}_{420} /\left(\mathrm{OD}_{600} \times 20 \mu \mathrm{l} \times 120 \mathrm{~min}\right)\right]$. Columns labelled with different letters are significantly different (Tukey's HSD test, $p \leq 0.01)$. Error bars show SE $(\mathrm{n}=6)$ 


\section{CRE1/AHK4 competitive assay}

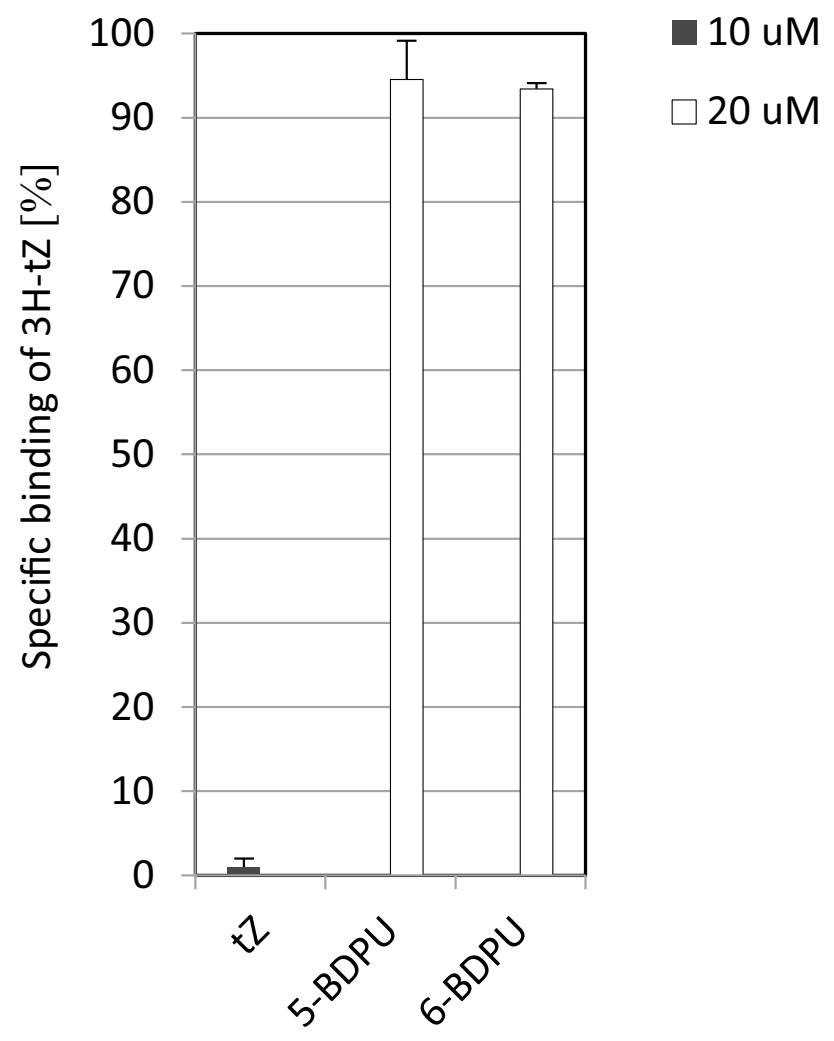

Fig. 9 Direct interaction of 5-BDPU and 6-BDPU with CRE1/AHK4 cytokinin receptor in a bacterial live-cell hormone-binding assay

\section{$\mathrm{ZmCKX} 1$}

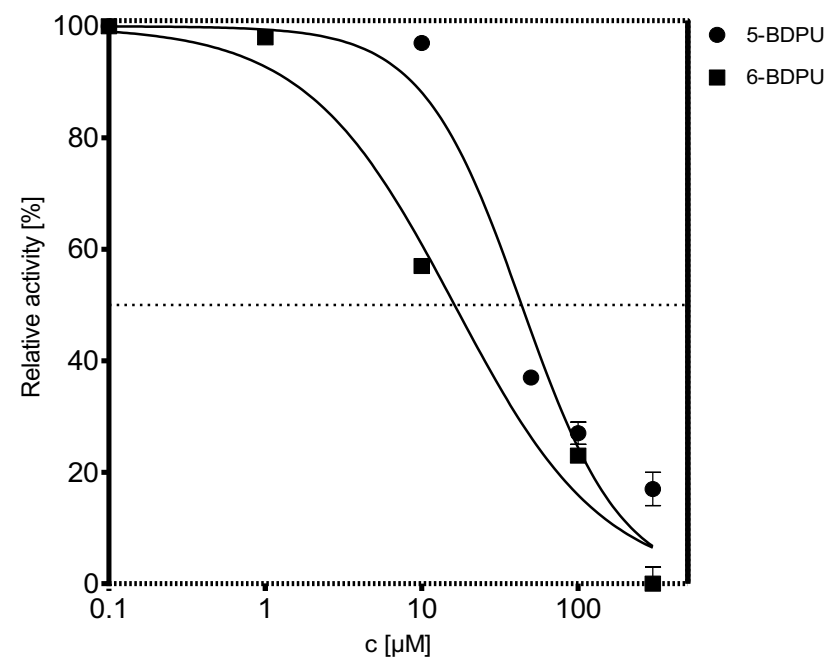

Fig. 10 Inhibition of the wild-type $\mathrm{ZmCKX} 1$ by 5-BDPU and 6-BDPU; IC50 values were measured by the initial rate DCPIP method with $10 \mu \mathrm{M} 2 \mathrm{iP}$ saturating substrate

\section{Docking simulations}

\section{Docking with CRE1/AHK4 receptor}

The Arabidopsis thaliana histidine kinase 4 receptor (CRE1/ AHK4) is a homodimeric membrane cytokinin receptor that contains a cytoplasmic histidine kinase module and an extracellular $\sim 270$-residue sensor domain that harbours the cytokinin-binding site. The N-terminus of the CRE1/AHK4 sensor domain folds into a long stalk helix connected by a shorter helix to two PAS-like domains (Hothorn et al. 2011). The membrane-distal PAS domain binds cytokinins in a pocket formed by a $\beta$-sheet floor lined by small hydrophobic residues. CRE1/AHK4 can bind both naturally occurring adenine-type cytokinins and urea-type synthetic compounds in the same site. A H-bond formed by the ligand with Asp262 seems to be critical for receptor function.

Looking at the crystal structures, by comparison with other PAS domains, we can identify a big loop-helix-loop lid (residues 245-274) and a small loop connecting $\beta C$ and $\beta \mathrm{D}$ strands (residues 282-288), jointly acting to keep the ligand into the binding site.

All the available complexes, even with different ligands, preserve an identical backbone conformation. In addition, all the sidechains of the binding site residues in the different complexes are perfectly superimposable (see also "Materials and methods" section), meaning that the different ligand typology does not affect the ligand neighbourhood, maintaining (or inducing) the same conformation of the site. This observation minimizes the docking simulation problems raising from the so-called "induced fit" of the binding site around the ligand.

As the natural cytokinin $2 \mathrm{iP}$ has one of the highest affinity for CRE1/AHK4 receptor (Romanov et al. 2006) and the highest relevance in our experimental results, it was chosen to validate the docking simulation parameters. The described similarity of binding site conformations in the presence of different ligands indicates that the choice of the compound for the reference docking simulation is not critical.

The docking simulations on $2 \mathrm{iP}$ correctly reproduce the position adopted in the crystal structure only if the $N(7)$ $\mathrm{H}$ tautomer of the adenine imidazole ring (Dreyfus et al. 1975 ) is considered. This fact is in agreement with the crystal structure of the complex, which shows the presence of an H-bond between N(7) of the imidazole ring and the carboxylate sidechain of Asp262 (Hothorn et al. 2011).

However, it is reported that some polar interactions established with the cytokinins are mediated by conserved water molecules (Hothorn et al. 2011; Lomin et al. 2012). In particular, two conserved molecules are involved in water bridges between the protein and two nitrogen atoms of the adenine ring (Hothorn et al. 2011), therefore we have performed a new docking simulation on $2 \mathrm{iP}$ keeping the two 
water molecules into the binding site. Again, the $\mathrm{N}(7) \mathrm{H}$ tautomer adopts the correct position, preserving the key interaction with Asp262. In addition, in the presence of water the intermolecular interaction energy $\left(E_{\mathrm{i}}\right)$ is slightly more favourable $(-8.17 \mathrm{vs} .-7.82 \mathrm{kcal} / \mathrm{mol}$ without any water).

A first set of docking simulations of 5-BDPU and 6-BDPU to CRE1/AHK4 receptor was carried out restricting the search of the binding mode in the conformational space of the cytokinin binding PAS domain, both in the presence and in the absence of conserved waters. The poses of the two BDPU molecules were found to be very similar.

In the absence of water inside the binding pocket, the conformational cluster analysis shows that the statistically most relevant binding mode (corresponding to the most populated cluster, that for 6-BDPU is also the one with the lowest energy, see also "Materials and methods" section) adopts a conformation outside the cytokinin binding site. In addition, almost all the other binding modes are out of the site; only in a small percentage of complexes (about $12 \%$ of the total conformations) the BDPUs are placed inside the binding pocket, forming the expected $\mathrm{H}$-bond between the urea nitrogen and the oxygen atom of Asp262.

The presence of the two conserved water molecules inside the binding site makes it difficult for the bulky BDPUs to enter the pocket. In this case, only the first very small cluster of 5-BDPU (6\% of the total population) presents a binding mode inside the binding pocket, but in a not canonical orientation, i.e. with the rings flipped around molecular axis and the urea nitrogen atoms far away from Asp262. In all the rest of clustered conformations, BDPUs find only poses spread at the surface of the domain.

For this reason, a second set of docking simulations were then carried out with BDPUs, enlarging the grid map to comprehend the whole surface of the dimeric receptor, with the aim of investigating a possible involvement of the domain interfaces and to evaluate the affinity of other sites with respect to the cytokinin binding pocket. Except for a very little cluster ( $0.8 \%$ of the total conformations) that shows the ligands inside the pocket, but in the flipped position, the simulations identified a low energy position behind the binding domain, adopted in both monomers along the cluster distribution. The results were then refined with a closely spaced grid around the new site (see Materials and Methods), finding for the two BDPUs exactly the same binding mode (Figs. 11 and 12). The two poses represent the $60 \%$ (for 5-BDPU) and 78\% (for 6-BDPU) of the total conformations, with an $E_{i}$ of -7.76 and $-8.2 \mathrm{kcal} / \mathrm{mol}$, respectively. In addition, all other poses in the other clusters are very similar to that one. In such favourable conformation, the ligand is positioned between the $\beta$-sheet edge close to the first loop of the lid and the stalk helix, near the dimer interface (Figs. 11 and 12a). Even if the 6-BDPU double ring is flipped in respect with 5-BDPU, the symmetry of

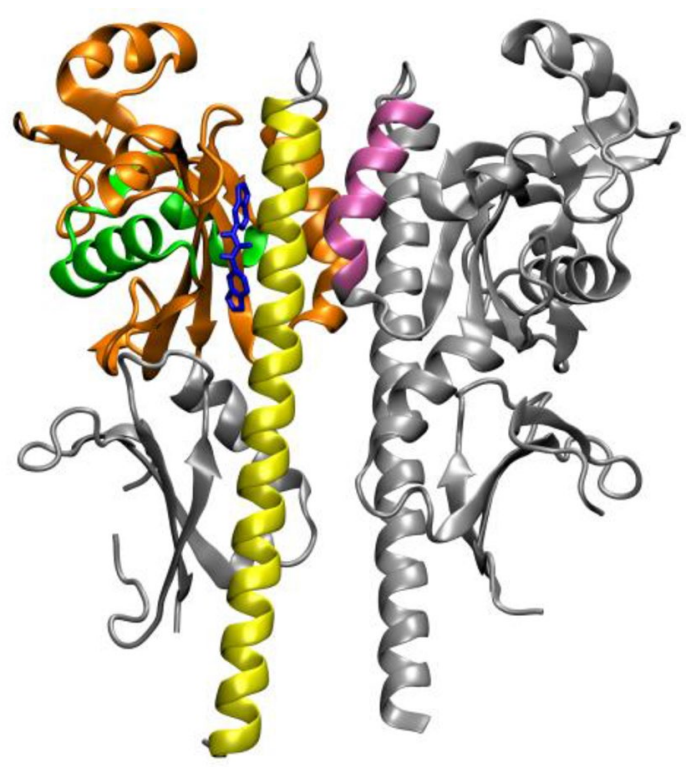

Fig. 11 Preferred complex of 5-BDPU with the dimeric structure of the AHK4 receptor, as obtained by the docking simulations. In orange is highlighted the cytokinin PAS binding domain of chain A, with its loop-helix-loop lid (in green); in yellow is the stalk helix of the same chain and in pink the shorter helix of the opposite chain $\mathrm{B}$. The 5-BDPU ligand is in blue. 5-BDPU is chosen as an example of the two BDPUs' identical complex conformations. (Color figure online)

the polar atoms is maintained, allowing the formation of the same H-bonds that, together with several hydrophobic interactions, involve both the $\beta$-sheet and the stalk helix (Fig. 12b). In particular, H-bonds are formed with Ser168, His 161, and the backbone of Gly273 and Ala275. However, the most interesting interaction is with R190 residue belonging to the other monomer and placed in the short helix at the dimer interface, that forms a H-bond and a cation- $\pi$ interaction (see the Materials and Methods section for the assessment criterion) with the BDPU molecules. This behaviour indicates a putative involvement of both chains in the ligand binding.

\section{Docking with CKX enzyme}

CKXs are monomeric enzymes belonging to the group of FAD-containing oxidoreductases (Schmülling et al. 2003), showing a two-domain topology, with a FAD-binding domain and a substrate-binding domain strictly connected. The isoalloxazine ring of the FAD cofactor is located at the interface of the two domains. As described in Materials and Methods section, several structures of CKX receptor are available in the PDB databank, 2 from Arabidopsis thaliana (all of type 7) and 21 from Zea mays. Therefore, for docking simulations we chose the only available cytokinin oxidase/ dehydrogenase type 7 of Arabidopsis (AtCKX7), and the 


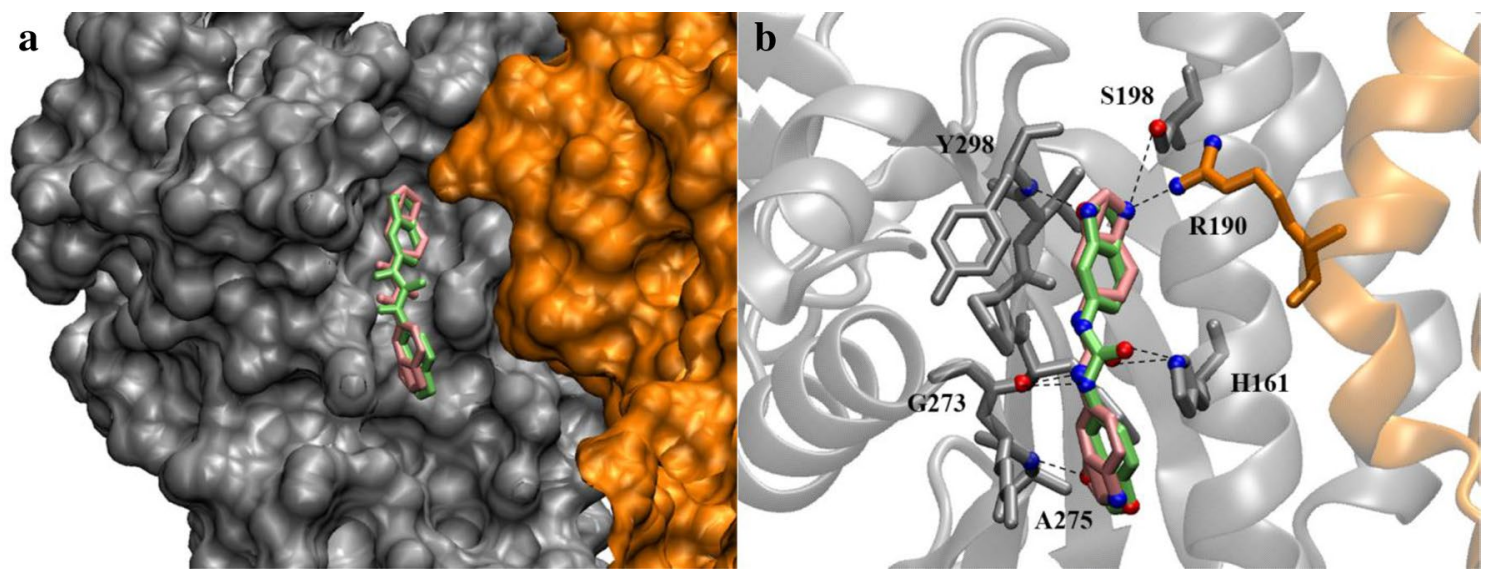

Fig. 12 a Molecular surface of the cavity hosting the BDPU ligands in the dimeric structure of the AHK4 receptor. 5-BDPU is in lime and 6-BDPU in pink; chain A and chain B are in silver and orange, respectively. b Residues interacting with BDPUs. The H-bonds are

maize CKX type 1 (ZmCKX1), the same used in inhibition experiments.

The $\mathrm{ZmCKX} 1$ structure $2 \mathrm{qkn}$ was chosen because it is complexed with N-phenyl-N'-(2-chloro-4-pyridyl)urea (CPPU), a urea-type competitive inhibitor structurally similar to BDPUs (Kopečný et al. 2010) that we have tested as a reference for docking simulations with this kind of receptor.

CPPU has a preferential binding mode in which the 2-chloro-4-pyridyl ring stacks against isoalloxazine plane of FAD cofactor, and urea backbone nitrogen atoms are hydrogen bonded to the side chain of Asp169, the residue involved in the catalytic mechanism. An additional H-bond is formed between Glu381 and the nitrogen of pyridyl ring. Several other tested inhibitors (Kopečný et al. 2010; Nisler et al. 2016) show a binding mode with a $\pi-\pi$ stacking of their

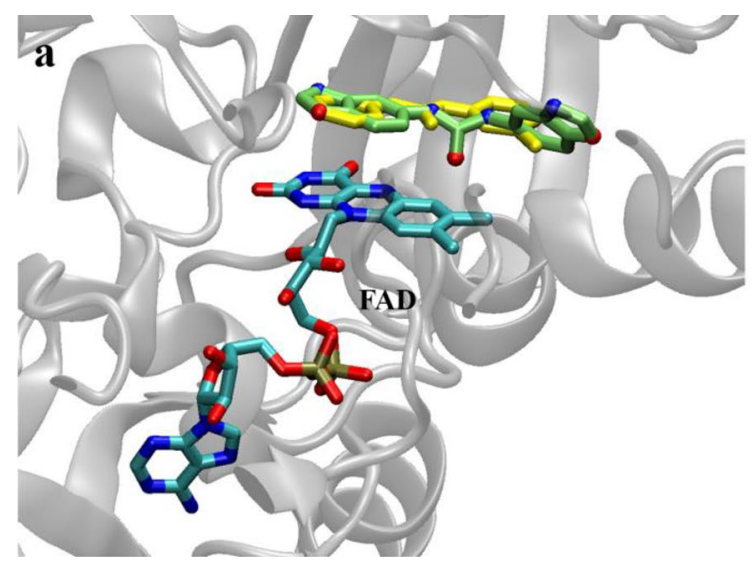

Fig. 13 a The 5-BDPU ligand (in lime, with polar atoms colored by type) docked inside the ZmCKX1 binding site. The conformation of CPPU in the crystal (in yellow) is overlaid. The stacking with FAD rings is evident. In this panel only 5-BDPU molecule is shown for highlighted in dashed lines. The colour scheme is the same of (a), with the polar atoms that form $\mathrm{H}$-bonds colored by type (red=oxygen, blue $=$ nitrogen $)$. (Color figure online $)$

aromatic ring on the FAD isoalloxazine ring. The CPPU docked into its binding site, in the presence of FAD ligand, recovers its correct binding mode forming all the aforementioned interactions, with $\mathrm{E}_{\mathrm{i}}=-8.49 \mathrm{kcal} / \mathrm{mol}$.

The BDPU ligands docked into the CKX binding site recover the same position as CPPU in the crystal, with one of the double ring groups in stacking with the FAD isoalloxazine ring (Fig. 13a), even if, as previously observed for the CRE1/AHK4 receptor, the 6-BDPU double ring is flipped in respect with 5-BDPU one. The other double ring is slightly rotated towards the entrance of the binding pocket. Even if the BDPU molecules are shifted in respect with CPPU, due to the different steric hindrance, one hydrogen bond between the urea nitrogen and the side chain of Asp169 is maintained, even if for 5BDPU it is slightly longer than for 6-BDPU. In

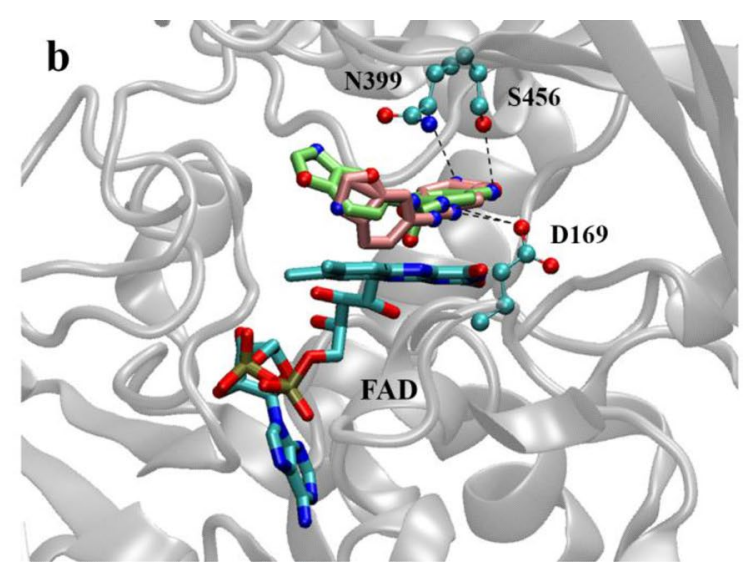

clarity. b Residues interacting with BDPUs (5-BDPU in lime and 6-BDPU in pink), colored by atom type. The H-bonds are again in dashed line. (Color figure online) 
addition, three other H-bonds are formed: between Asn399 and an oxygen atom of the oxazole ring; between the Ser456 and the nitrogen atom of the same ring; between the oxygen atom of urea and the FAD isoalloxazine ring (Fig. 13). The $\mathrm{E}_{\mathrm{i}}$ of the best complex (with a very high cluster population, from $64 \%$ of the total conformations of 5-BDPU to $67 \%$ of 6-BDPU) is of $-8.44 \mathrm{kcal} / \mathrm{mol}$ for 5 -BDPU and $-8.57 \mathrm{kcal} /$ mol for 6-BDPU, therefore very similar to CPPU one.

AtCKX isoform 7 was used in the docking experiments because, as we said, it is the only crystal structure of AtCKX currently available. Both the available crystal structures of AtCKX7 contain the FAD, but do not have any molecule inside the substrate-binding domain. Interestingly, the substrate binding site is almost perfectly superimposable with the one of ZmCKX1 (Bae et al. 2008), even if not all the residues of the binding cavity are strictly conserved. This could indicate that binding does not considerably influence the site architecture, as reported also by Kopečný and coworkers (Kopečný et al. 2016).

Our docking of BDPUs on the AtCKX7 2exr structure produced in both cases a unique cluster, that is a unique binding mode, in which BDPU molecules form a $\pi-\pi$ stacking with the FAD isoalloxazine ring, in an almost identical way as in ZmCKX1 enzyme, with a $\mathrm{E}_{\mathrm{i}}$ of $-8.73 \mathrm{kcal} / \mathrm{mol}$ for 5-BDPU and $-9.0 \mathrm{kcal} / \mathrm{mol}$ for 6-BDPU. In addition, the H-bond with the catalytic Asp162 (Asp169 in Zea mays) is still conserved (Fig. 14), as well as the other H-bonds, with the exception of the one involving Ser456 (Zea mays numbering) that here is substituted by Ala441.

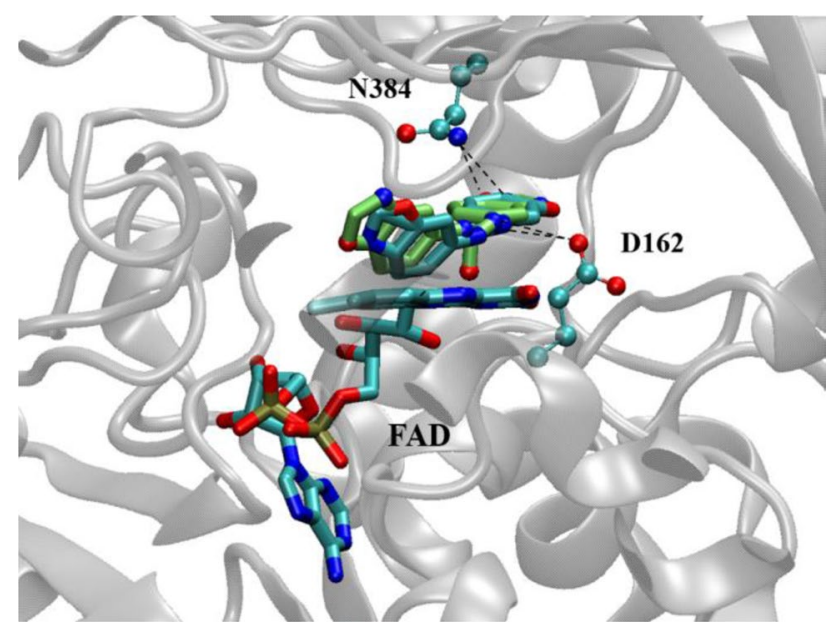

Fig. 14 The BDPU ligands docked inside the AtCKX7 binding site. Again, the stacking of a double ring with FAD rings is evident. Residues interacting with BDPUs are labelled and colored as in Fig. 12, as well as H-bonds. (Color figure online)

\section{Discussion}

In the past few years, starting from previous structure-activity relationship studies and results, we have reported that two synthetic urea derivatives, the 5-BDPU and the 6-BDPU, act as adventitious rooting adjuvants and 5-BDPU as xylogenesis enhancer, without showing auxin- or cytokinin-like activity per se (Brunoni et al. 2014; Ricci et al. 2006, 2016). We also demonstrated that these effects depend on their capacity to somehow magnify the activity of auxins, which therefore need to be simultaneously present in the experimental culture system. But, as it is well known that not only auxins but even cytokinins play important roles in plant cell growth and development, we would like to verify if BDPUs could interact directly and/or indirectly also with cytokinins. Thus, setting up a variety of biological assays increasingly accurate, together with predictive computational studies, we tried to analyze the extent of BDPU action spectrum, as nothing has been previously reported about their possible adjuvant activity exerted on cytokinins. As we completely ignored the type of the potentially existing interaction, we planned a multi-faced approach, in order to verify if BDPUs could somehow interfere with cytokinin behaviour and their-driven effects. Thus, depending on the specificity of the bioassays, structurally diverse adenine-type cytokinins, i.e. 2iP, BAP, tZ, and TDZ, a synthetic urea-type cytokinin, were used in mixture with BDPUs. In addition to their chemical structure, these cytokinins were chosen accordingly to their different in planta metabolism; in fact, $2 \mathrm{iP}$ and $\mathrm{tZ}$ are degraded by cytokinin oxidase/dehydrogenase (CKX), while BAP is resistant to CKX cleavage and TDZ non-competitively inhibits the enzyme (Kieber and Schaller 2014).

\section{Plant development}

This adaptable bioassay has been used to compare the effects of different concentrations of 5-BDPU and 6-BDPU to that of 2iP, BAP and TDZ on Arabidopsis seedling development either alone or in mixtures. Cytokinin-treated plants show a strong reduction of shoot development, morphological leaf alterations and/or abnormalities, anthocyanin accumulation, inhibition of root growth, in a concentration- and supplementation length-dependent way, as expected. The occurrence of these alterations also depends on the type of cytokinin, being evident even at the lowest concentration of $\mathrm{BAP}$, while a higher concentration is required for TDZ and even higher for 2iP. The effects of 5-BDPU and 6-BDPU are not comparable to that of cytokinin-treated plants, rather they are similar to that of non-treated control plants (HF and DMSO conditions). Thus, these morphological qualitative results confirm that 5-BDPU and 6-BDPU do not function as cytokinins, and it is impossible to point out a hypothetical 
interaction with endogenous cytokinins. When Arabidopsis seeds are sown in the presence of mixtures of compounds, i.e. exogenous cytokinins plus 5-BDPU or 6-BDPU, the resulting plant development is negatively affected. In fact, the same alterations and abnormalities cited above are more evident than the ones caused by the corresponding cytokinin concentration alone, being more severe in the presence of BAP and TDZ.

\section{Root elongation inhibition assay}

This simple but also specific bioassay has been used to evaluate either the effect of 5-BDPU and 6-BDPU alone or their hypothetical adjuvant effect towards the inhibition of root elongation, a typical cytokinin-related process. Our results clearly prove that 5-BDPU and 6-BDPU alone do not show cytokinin-like activity. Rather they magnify the inhibition of root elongation caused by all the concentrations of $2 \mathrm{iP}$ and BAP, natural cytokinins, and by the highest concentrations of TDZ, a synthetic urea-type cytokinin. Thus, the simultaneous supplementation of 5-BDPU or 6-BDPU affect this specific physiological process, making the cytokinindependent inhibition effect significantly more severe. Also, it seems that the adjuvant effect differs according to type of cytokinin, i.e. natural or synthetic.

\section{Amaranthus seedling test}

This highly specific bioassay has been used to confirm the adjuvant effect of 5-BDPU and 6-BDPU demonstrated by the root elongation inhibition assay. On the contrary, the betacyanin content is not significantly affected by the simultaneous presence of cytokinins and urea derivatives (completely ineffective when supplemented alone). This could be tentatively explained by the different efficacy and/or target of this bioassay and by the relatively fast response (results are collected after a few hours).

\section{Shoot regeneration assay}

This versatile in vitro tomato shoot regeneration protocol has been used to assay the cytokinin-like activity of whatever compound, performing a reproducible shooting response, highly medium-dependent. Our data confirm that 5-BDPU does not show any cytokinin-like activity per se, but exerts an adjuvant activity clearly evident when it is added to $2 \mathrm{iP}$. The absence of any adjuvant effect when 5-BDPU is added to BAP and/or TDZ could be once more dependent to the type and/or the activity of cytokinins in this complex metabolic system. As BAP is resistant to CKX cleavage and TDZ non-competitively inhibits the enzyme, they probably exert a strong long-lasting cytokinin activity in this long time assay, thus making the hypothetical enhancement or adjuvant activity of 5-BDPU not clearly detectable and/or insignificant.

\section{Interaction of BDPUs with proteins involved in cytokinin perception and degradation}

\section{Cytokinin perception}

In Arabidopsis thaliana three transmembrane histidine kinases, namely AHK2, AHK3, and CRE1/AHK4, serve as cytokinin receptors (Inoue et al. 2001; Suzuki et al. 2001; Ueguchi et al. 2001; Yamada et al. 2001). They are expressed in almost all tissues, acting redundantly in cytokinin signalling, even if they differently contribute to different processes (Riefler et al. 2006; Stolz et al. 2011). The CRE1/AHK4 was the only one of the three cytokinin receptors used in this study, as it has previously reported (i) that it exerts a dominating role in cytokinin-induced inhibition of primary root growth (Higuchi et al. 2004), (ii) that it gives a major contribution to the in vitro shoot regeneration process (Riefler et al. 2006 and references herein), (iii) that it provokes a several fold higher response in Escherichia coli than AHK3, with the highest affinity for $2 \mathrm{iP}$ (Spíchal et al. 2004), (iv) that in planta transmission of a cytokinin signal through AHK3 and AHK2 was several fold lower than through CRE1/AHK4 (Hwang and Sheen 2001), (v) that AHK2 and CRE1/AHK4 have similar ligand preferences (Stolz et al. 2011). From our results, we can infer that BDPUs do not activate the CRE1/AHK4 cytokinin receptor, as no direct interaction with CRE1/AHK4 was recorded in the direct completion assay and no $\beta$-galactosidase activity was detected when the compounds were tested alone in the heterologous bacterial assay. On the contrary, their presence in the mixture cytokinin plus BDPU, regardless their concentration, magnify the receptor activation shown by each cytokinin alone, i.e. $2 \mathrm{iP}, \mathrm{BAP}$ or TDZ. This could be consistent with a peculiar interaction, allowed only by the simultaneous presence of the three actors: cytokinin, CRE1/AHK4 receptor, BDPU.

$A R R 5$ is a type-A Arabidopsis Response Regulator gene showing the greatest fold-induction in response to cytokinin (D'Agostino et al. 2000; Rashotte et al. 2003) and it has been used to monitor in planta specific sites and patterns of cytokinin distribution and/or to investigate the auxin-cytokinin interaction (To et al. 2004; Kakani 2011; Zhang et al. 2014). Even if the information obtained is not quantitative but only qualitative, it is widely accepted that the visualization of staining intensity and/or extent and the appearance of new sites of staining is strictly dependent on the different treatments the seedlings have undergone. While the 5-BDPU is ineffective alone, by our images it is possible to visualize a clear adjuvant effect of 5-BDPU when added to $2 \mathrm{iP}$ in the form of altered spatial expression of ARR $5:: G U S$ in the primary root, as the blue staining is stronger and wider than 
in the corresponding control condition. The adjuvant effect is only partially evident or even unclear when 5-BDPU is added to TDZ. Besides, in our experimental conditions, GUS is so abundantly expressed in the primary root tissues in the presence of BAP that it is impossible to visualize any adjuvant effect due to 5-BDPU presence. By the way, this situation resembles that observed in the previous in vitro shoot regeneration assay. As ARR5 transcription is upregulated by cytokinins in a dosage-dependent manner, we suppose that 5-BDPU could modify cell sensitivity to cytokinins affecting their signalling pathway, interfering with their receptor(s) and/or inhibiting the cytokinin oxidase/ dehydrogenase activity.

\section{Cytokinin degradation}

Through the enzymatic experiments we showed that BDPUs are capable of inhibition of CKX. Both the compounds were able to inhibit activity of ZmCKX1 reaching IC50 values comparable to the previously published derivatives of CPPU (Kopečný et al. 2010) and TDZ (Nisler et al. 2016).

\section{Docking simulations}

CRE1/AHK4 receptor is a homodimer in crystal, reflecting the behaviour of histidine kinases, in which signalling is not mediate by dimerization of kinase domains, but rather, it is believed that perception of stimuli causes alteration of protein-protein interactions within the preformed dimer surface and that these perturbations are relayed to the kinase core domain (Gao and Stock 2009). Therefore, it is useful to investigate the interaction of BDPUs with the dimer already conformed by the presence of cytokinin into the binding site - as the chosen receptor structure is.

The docking results are in agreement with what observed by the experiments. The intermolecular interaction energy of BDPUs with the receptor is comparable with the one of the endogenous $2 \mathrm{iP}$, but the binding of BDPUs inside the cytokinin pocket is statistically very unfavorable, confirming and justifying the absence of cytokinin-like action of BDPUs alone.

Instead, the docking exploration of the whole dimeric structure evidences the presence of a site among the binding PAS domain, the stalk helix and the dimer interface. Due to their steric hindrance, BDPUs could block the movement of the lid opening or the re-adaption of the structurally perturbed interface, which could release the cytokinin molecule. The effect of this blocking could be the higher persistence of cytokinin in its binding pocket and the subsequent enhancing of its kinase action.

To give more structural insights into the inhibition of a cytokinin oxidase/dehydrogenase, docking simulations of BDPUs both on the maize and Arabidopsis CKX structures were performed and compared with the behavior of CPPU inhibitor. Not only the orientation and several key interactions are conserved, but also the intermolecular interaction energy is comparable.

Finally, also the intermolecular interaction energy of the BDPU-CRE1/AHK4 complex with the one of BDPU-CKX is comparable, indicating that both the interactions can contemporarily occur.

\section{Conclusions}

In this manuscript we demonstrate for the first time that 5-BDPU and 6-BDPU exert an adjuvant activity on some natural adenine- and/or synthetic urea-type cytokinin-driven effects. The 2iP-related effects are enhanced by the simultaneous presence of 5-BDPU and 6-BDPU, with the only exception of the betacyanin accumulation that is not affected by their presence. The BAP-dependent alteration of plant development and the inhibition effect on root elongation are enhanced by the simultaneous presence of 5-BDPU and 6-BDPU, while betacyanin accumulation, shoot regeneration and GUS activity in transgenic plants are not affected by their presence. The TDZ-dependent alteration of plant development is enhanced by the simultaneous presence of 5-BDPU and 6-BDPU, while the inhibition effect on root elongation as well as GUS activity in transgenic plants are partially enhanced by their simultaneous presence, on the contrary betacyanin accumulation and shoot regeneration are not affected. Thus, by our results we can infer that the adjuvant activity depends on the type of cytokinin supplemented and, keeping in mind the intrinsic shortcomings that characterize each bioassay (Mok 1994), it is clearly provable only in some of them. In fact, completely negative results, as that obtained with each of the 3 cytokinins plus BDPUs by the Amaranthus seedling test, demonstrate that it is necessary to use bioassays that differ each other in target, signalling pathway, length of detection time. About the latter, using extremely rapid bioassays, as Amaranthus assay, or very long responsive ones, as regeneration assay, can cause important loss of information, as we have experienced.

Moreover, the circumstance that the adjuvant activity is clearly shown only in the simultaneous presence of exogenously supplemented cytokinins led us to try to verify the existence of a structural relationship among cytokinincytokinin receptor-BDPU. By docking simulations, we have seen that BDPUs unfavourably bind into the cytokinin binding pocket of CRE1/AHK4 receptor, as it could be inferred by the results obtained by the heterologous bacterial assay, in agreement with the absence of a cytokinin-like activity per se, as previously reported (Ricci et al. 2006, 2016; Brunoni et al. 2014) and further demonstrated here. Rather, quite interestingly, by the docking simulation results 
we hypothesize that the tripartite system, cytokinin-CRE1/ AHK4 receptor-BDPU, could be another example of allosteric interaction (Kumari and Van der Hoorn 2011). In fact, it was reported that cytokinin binding to the CRE1/AHK4 pocket causes conformational changes, that involve the protein-protein interaction at the dimer surface (Gao and Stock 2009). Likely, also the lid—or a portion of it—could be involved in an opening/closure movement. Consequently, this change creates an outer surface on which BDPU is able to bind favourably, blocking the lid movement and/or the readjusting of the dimer interface. This could probably favour the persistence of the cytokinin inside the pocket, having an effect similar to an enhanced affinity.

In addition, we cannot exclude that BDPUs could inhibit cytokinin oxidase/dehydrogenase (CKX) that inactivates cytokinins in planta. This hypothesis originates from two distinct aspects: first, their effectiveness is much more evident towards $2 \mathrm{iP}$, naturally degraded by CKX, rather than $\mathrm{BAP}$, resistant to CKX cleavage, or TDZ, non-competitively inhibiting the enzyme; second, their urea-type chemical structure resembles that of other urea derivatives, that inhibit CKX (Nisler et al. 2016). By docking simulation, we have demonstrated that BDPUs favourably binds into the binding pocket of the enzyme possibly preventing its effect of inactivation of natural adenine-type cytokinin with isoprenoid side chain. By CKX inhibition measurements using ZmCKX1, we experimentally proved that BDPUs can increase the lifetime of cytokinins in planta.

In the end, the biological assays and the docking simulations both show that the adjuvant activity exerted by BDPUs towards some cytokinin-driven physiological effects could be due to a combination of two interactions: a binding to the surface of CRE1/AHK4 receptor, and a binding into the active site of CKX. Incidentally, a dual activity is not surprising, as it has already been reported for other urea-type compounds, as TDZ and CPPU (Kopečný et al. 2010).

But, still, many questions are unanswered: (i) do BDPUs remain in the apoplast, inhibiting apoplastic CKXs and binding to the small population of CRE1/AHK4 receptor located in the plasma membrane? (ii) do BDPUs enter the cells exerting their dual activity towards CKXs and CRE1/ AHK4 receptor located at subcellular level? And in the case, do they need specific influx carriers for their uptake into the cells? (iii) do BDPUs exert their adjuvant activity on other important cytokinin-driven effects, as leaf senescence delay, nutrient balance and/or stress responses?

Work is in progress to answer these questions and further studies are required to verify if, thanks to their contemporary dual effect, even BDPUs could be positively employed in biotechnology, cosmetics, precise agricultural practice as recently suggested for natural cytokinins and synthetic cytokinin-like compounds (Oshchepkov et al. 2020).
Supplementary Information The online version contains supplementary material available at https://doi.org/10.1007/s10725-021-00735-3.

Acknowledgements We thank prof. Giorgio Pelosi (University of Parma) for helpful discussions on the manuscript.

Author contributions $A R$ conceived the research and wrote the manuscript; $A R, F B, E R$ and $L S$ carried out the biological experiments; $E P$ carried out the docking simulations; $E P$ and $L S$ contributed also to the discussion.

Funding Open access funding provided by Università degli Studi di Parma within the CRUI-CARE Agreement. This work was supported by Local Funding for Research (FIL funds), University of Parma, to AR, and benefits from the HPC (High Performance Computing) facility of the University of Parma, Italy to EP. This work was also supported by ERDF grant project No. CZ.02.1.01/0.0/0.0/16_019/00008 27 (Plants as a tool for sustainable global development) to LS.

\section{Declarations}

Conflict of interest The authors declare that the research was conducted in the absence of any relationships that could be construed as a potential conflict of interest.

Open Access This article is licensed under a Creative Commons Attribution 4.0 International License, which permits use, sharing, adaptation, distribution and reproduction in any medium or format, as long as you give appropriate credit to the original author(s) and the source, provide a link to the Creative Commons licence, and indicate if changes were made. The images or other third party material in this article are included in the article's Creative Commons licence, unless indicated otherwise in a credit line to the material. If material is not included in the article's Creative Commons licence and your intended use is not permitted by statutory regulation or exceeds the permitted use, you will need to obtain permission directly from the copyright holder. To view a copy of this licence, visit http://creativecommons.org/licenses/by/4.0/.

\section{References}

Armstrong DJ (1994) Cytokinin oxidase and the regulation of cytokinin degradation. In: Mok DW, Mok MC (eds) Cytokinin: chemistry, activity, and function. CRC, Boca Raton, pp 139-154

Bae E, Bingman CA, Bitto E et al (2008) Crystal structure of Arabidopsis thaliana cytokinin dehydrogenase. Proteins Struct Funct Genet. https://doi.org/10.1002/prot.21678

Bai F, Demason DA (2008) Hormone interactions and regulation of PsPK2:GUS compared with DR5:GUS and PID:GUS in Arabidopsis thaliana. Am J Bot 95:133-145. https://doi.org/10.3732/ Ajb.95.2.133

Berman HM, Westbrook J, Feng Z et al (2000) The Protein Data Bank. Nucleic Acids Res 28:235-242

Box GEP, Cox DR (1964) An analysis of transformations. J R Stat Soc Ser B. https://doi.org/10.2307/2287791

Brunoni F, Rolli E, Dramis L et al (2014) Adventitious rooting adjuvant activity of 1,3-di(benzo[d]oxazol-5-yl)urea and 1,3-di(benzo[d] oxazol-6-yl)urea: new insights and perspectives. Plant Cell Tissue Organ Cult 118:111-124. https://doi.org/10.1007/ s11240-014-0466-8

Caesar K, Thamm AMK, Witthöft J et al (2011) Evidence for the localization of the Arabidopsis cytokinin receptors AHK3 and AHK4 
in the endoplasmic reticulum. J Exp Bot 62:5571-5580. https:// doi.org/10.1093/jxb/err238

Carra A, De Pasquale F, Ricci A, Carimi F (2006) Diphenylurea derivatives induce somatic embryogenesis in Citrus. Plant Cell Tissue Organ Cult 87:41-48. https://doi.org/10.1007/s11240-006-9132-0

D'Agostino IB, Deruère J, Kieber JJ (2000) Characterization of the response of the Arabidopsis response regulator gene family to cytokinin. Plant Physiol 124:1706-1717. https://doi.org/10.1104/ pp.124.4.1706

Davis IW, Leaver-Fay A, Chen VB et al (2007) MolProbity: all-atom contacts and structure validation for proteins and nucleic acids. Nucleic Acids Res. https://doi.org/10.1093/nar/gkm216

Dreyfus M, Dodin G, Bensaude O, Dubois JE (1975) Tautomerism of purines. I. $\mathrm{N}(7) \mathrm{H} \rightleftharpoons \mathrm{N}(9) \mathrm{H}$ equilibrium in adenine. J Am Chem Soc. https://doi.org/10.1021/ja00842a011

Duclercq J, Sangwan-Norreel B, Catterou M, Sangwan RS (2011) De novo shoot organogenesis: from art to science. Trends Plant Sci 16:597-606. https://doi.org/10.1016/j.tplants.2011.08.004

Durán-Medina Y, Díaz-Ramírez D, Marsch-Martínez N (2017) Cytokinins on the move. Front Plant Sci. https://doi.org/10.3389/fpls. 2017.00146

Galuszka P, Frébort I, Šebela M et al (2001) Cytokinin oxidase or dehydrogenase? Mechanism of cytokinin degradation in cereals. Eur J Biochem. https://doi.org/10.1046/j.1432-1033.2001.01910.x

Gao R, Stock AM (2009) Biological insights from structures of twocomponent proteins. Annu Rev Microbiol 63:133-154. https://doi. org/10.1146/annurev.micro.091208.073214

Gaspar T, Kevers C, Penel C et al (1996) Plant hormones and plant growth regulators in plant tissue culture. Vitro Cell Dev Biol Plant 32:272-289. https://doi.org/10.1007/BF02822700

Gasteiger J, Marsili M (1980) Iterative partial equalization of orbital electronegativity - a rapid access to atomic charges. Tetrahedron 36:3219-3228

Guex N, Peitsch MC (1997) SWISS-MODEL and the Swiss-PdbViewer: an environment for comparative protein modeling. Electrophoresis 18:2714-2723

Hanwell MD, Curtis DE, Lonie DC et al (2012) Avogadro: an advanced semantic chemical editor, visualization, and analysis platform. J Cheminform 4:17. https://doi.org/10.1186/1758-2946-4-17

Herráez A (2006) Biomolecules in the computer: Jmol to the rescue. Biochem Mol Biol Educ 34(4):255-261

Higuchi M, Pischke MS, Ari PM et al (2004) In planta functions of the Arabidopsis cytokinin receptor family. Proc Natl Acad Sci USA 101(23):8821-8826

Hönig M, Plíhalová L, Husičková A et al (2018) Role of cytokinins in senescence, antioxidant defence and photosynthesis. Int J Mol Sci 19(12):4045

Hothorn M, Dabi T, Chory J (2011) Structural basis for cytokinin recognition by Arabidopsis thaliana histidine kinase 4. Nat Chem Biol 7:766-768. https://doi.org/10.1038/nchembio.667

Houba-Hérin N, Pethe C, D'Alayer J, Laloue M (1999) Cytokinin oxidase from Zea mays: purification, cDNA cloning and expression in moss protoplasts. Plant J. https://doi.org/10.1046/j.1365-313X. 1999.00408.x

Humphrey W, Dalke A, Schulten K (1996) VMD: visual molecular dynamics. J Mol Graph 14:33-38

Hwang I, Sheen J (2001) Two-component circuitry in Arabidopsis cytokinin signal transduction. Nature 413:383-389. https://doi. org/10.1038/35096500

Inoue T, Higuchi M, Hashimoto $\mathrm{Y}$ et al (2001) Identification of CRE1 as a cytokinin receptor from Arabidopsis. Nature 409:1060-1063. https://doi.org/10.1038/35059117

Kakani A (2011) ARR5 and ARR6 mediate tissue specific cross-talk between auxin and cytokinin in Arabidopsis. Am J Plant Sci 02:549-553. https://doi.org/10.4236/ajps.2011.24065
Kieber JJ, Schaller GE (2014) Cytokinins Arabidopsis Book 12:e0168. https://doi.org/10.1199/tab.0168

Kopečný D, Pethe C, Šebela M et al (2005) High-level expression and characterization of Zea mays cytokinin oxidase/dehydrogenase in Yarrowia lipolytica. Biochimie. https://doi.org/10.1016/j.biochi. 2005.04.006

Kopečný D, Briozzo P, Popelková H et al (2010) Phenyl- and benzylurea cytokinins as competitive inhibitors of cytokinin oxidase/ dehydrogenase: a structural study. Biochimie 92:1052-1062. https://doi.org/10.1016/j.biochi.2010.05.006

Kopečný D, Končitíková R, Popelka H et al (2016) Kinetic and structural investigation of the cytokinin oxidase/dehydrogenase active site. FEBS J. https://doi.org/10.1111/febs.13581

Kumari S, Van der Hoorn RAL (2011) A structural biology perspective on bioactive small molecules and their plant targets. Curr Opin Plant Biol 14:480-488

Lomin SN, Yonekura-Sakakibara K, Romanov GA, Sakakibara H (2011) Ligand-binding properties and subcellular localization of maize cytokinin receptors. J Exp Bot 62:5149-5159. https://doi. org/10.1093/jxb/err220

Lomin SN, Krivosheev DM, Steklov MY et al (2012) Receptor properties and features of cytokinin signaling. Acta Nat 4:31-45

Lomin SN, Krivosheev DM, Steklov MY et al (2015) Plant membrane assays with cytokinin receptors underpin the unique role of free cytokinin bases as biologically active ligands. J Exp Bot 66:18511863. https://doi.org/10.1093/jxb/eru522

Lomin SN, Myakushina YA, Arkhipov DV et al (2017) Studies of cytokinin receptor-phosphotransmitter interaction provide evidences for the initiation of cytokinin signaling in the endoplasmic reticulum. Funct Plant Biol 45(2):192-202

Mattsson J, Ckurshumova W, Berleth T (2003) Auxin signaling in Arabidopsis leaf vascular development. Plant Physiol 131:13271339. https://doi.org/10.1104/pp.013623.patterns

Miller JH (1972) Experiments in molecular genetics, vol 433. Cold Spring Harbor Laboratory Press, Cold Spring Harbor, pp 352-355

Miller CO, Skoog F, Von Saltza MH, Strong FM (1955) Kinetin, a cell division factor from deoxyribonucleic acid. J Am Chem Soc. https://doi.org/10.1021/ja01610a105

Mok MC (1994) Cytokinins and plant development-an overview. In: Mok DWS (ed) Cytokinins: chemistry, activity, and function, 1st edn. CRC Press, Boca Raton, pp 155-166

Morris GM, Goodsell DS, Halliday RS et al (1998) Automated docking using a Lamarckian genetic algorithm and an empirical binding free energy function. J Comput Chem 19:1639-1662

Morris RO, Bilyeu KD, Laskey JG, Cheikh NN (1999) Isolation of a gene encoding a glycosylated cytokinin oxidase from maize. Biochem Biophys Res Commun. https://doi.org/10.1006/bbrc. 1999.0199

Morris GM, Huey R, Lindstrom W et al (2009) AutoDock4 and AutoDockTools4: automated docking with selective receptor flexibility. J Comput Chem 30:2785-2791. https://doi.org/10.1002/jcc.21256

Motte H, Galuszka P, Spíchal L et al (2013) Phenyl-adenine, identified in a LIGHT-DEPENDENT SHORT HYPOCOTYLS4-assisted chemical screen, is a potent compound for shoot regeneration through the inhibition of CYTOKININ OXIDASE/DEHYDROGENASE activity. Plant Physiol 161:1229-1241. https://doi.org/ 10.1104/pp.112.210716

Motte H, Vereecke D, Geelen D, Werbrouck S (2014) The molecular path to in vitro shoot regeneration. Biotechnol Adv 32:107-121

Murashige T, Skoog F (1962) A revised medium for rapid growth and bioassays with tobacco tissue cultures. Physiol Plant 15:473-497

Nisler J (2018) TDZ: mode of action, use and potential in agriculture. In: Thidiazuron: from urea derivative to plant growth regulator. Springer, Singapore 
Nisler J, Zatloukal M, Popa I et al (2010) Cytokinin receptor antagonists derived from 6-benzylaminopurine. Phytochemistry. https:// doi.org/10.1016/j.phytochem.2010.01.018

Nisler J, Kopečný D, Končitíková R et al (2016) Novel thidiazuronderived inhibitors of cytokinin oxidase/dehydrogenase. Plant Mol Biol 92:235-248. https://doi.org/10.1007/s11103-016-0509-0

Nisler J, Zatloukal M, Sobotka R et al (2018) New urea derivatives are effective anti-senescence compounds acting most likely via a cytokinin-independent mechanism. Front Plant Sci. https://doi. org/10.3389/fpls.2018.01225

Nisler J, Kopečný D, Pěkná Z et al (2021) Diphenylurea-derived cytokinin oxidase/dehydrogenase inhibitors for biotechnology and agriculture. J Exp Bot. https://doi.org/10.1093/jxb/eraa437

Oshchepkov MS, Kalistratova AV, Savelieva EM et al (2020) Natural and synthetic cytokinins and their applications in biotechnology, agrochemistry and medicine. Russ Chem Rev. https://doi.org/10. 1070/rcr4921

Pettersen EF, Goddard TD, Huang CC et al (2004) UCSF Chimeraa visualization system for exploratory research and analysis. $\mathrm{J}$ Comput Chem 25:1605-1612. https://doi.org/10.1002/jcc.20084

Pierik RLM (1987) In vitro culture of higher plants. Matinus Nijhoff, Dordrecht

R Core Team (2013) R: a language and environment for statistical computing. R Core Team, Vienna

Rashotte AM, Carson SDB, To JPC, Kieber JJ (2003) Expression profiling of cytokinin action in Arabidopsis. Plant Physiol 132:19982011. https://doi.org/10.1104/pp.103.021436

Ricci A, Bertoletti C (2009) Urea derivatives on the move: cytokininlike activity and adventitious rooting enhancement depend on chemical structure. Plant Biol 11:262-272. https://doi.org/10. 1111/j.1438-8677.2008.00165.x

Ricci A, Rolli E (2020) Some urea derivatives positively affect adventitious root formation: old concepts and the state of the art. Plants $9(3): 321$

Ricci A, Carra A, Torelli A et al (2001a) Cytokinin-like activity of N, $\mathrm{N}^{\prime}$-diphenylureas. N, N'-bis-(2,3-methylenedioxyphenyl)urea and $\mathrm{N}, \mathrm{N}^{\prime}$-bis-(3,4-methylenedioxyphenyl)urea enhance adventitious root formation in apple rootstock M26 (Malus pumila Mill.). Plant Sci 160:1055-1065. https://doi.org/10.1016/S0168-9452(01) 00359-4

Ricci A, Carra A, Torelli A et al (2001b) Cytokinin-like activity of N'-substituted N-phenylureas. Plant Growth Regul 34:167-172

Ricci A, Carra A, Rolli E et al (2003) N, N'-bis-(2,3methylenedioxyphenyl)urea and N, $\mathrm{N}^{\prime}$-bis-(3,4methylenedioxyphenyl)urea interact with auxin in enhancing root formation of M26 apple (Malus pumila Mill.) stem slices. Plant Growth Regul 40:207-212. https://doi.org/10.1023/A:10250 45213739

Ricci A, Incerti M, Rolli E et al (2006) Diheteroarylurea derivatives as adventitious rooting adjuvants in mung bean shoots and M26 apple rootstock. Plant Growth Regul 50:201-209

Ricci A, Rolli E, Dramis L, Diaz-Sala C (2008) N, N'-bis(2,3-Methylenedioxyphenyl)urea and N, N'-bis-(3,4methylenedioxyphenyl)urea enhance adventitious rooting in Pinus radiata and affect expression of genes induced during adventitious rooting in the presence of exogenous auxin. Plant Sci 175:356363. https://doi.org/10.1016/j.plantsci.2008.05.009

Ricci A, Rolli E, Brunoni F et al (2016) 1,3-di(benzo[d]oxazol-5-yl) urea acts as either adventitious rooting adjuvant or xylogenesis enhancer in carob and pine microcuttings depending on the presence/absence of exogenous indole-3-butyric acid. Plant Cell Tissue Organ Cult 126:411-427. https://doi.org/10.1007/ s11240-016-1010-9

Riefler M, Novak O, Strnad M et al (2006) Arabidopsis cytokinin receptor mutants reveal functions in shoot growth, leaf senescence, seed size, germination, root development, and cytokinin metabolism. Plant Cell 18:40-54. https://doi.org/10.1105/tpc.105. 037796

Romanov GA, Getman IA, Schmülling T (2000) Investigation of early cytokinin effects in a rapid Amaranthus seedling test. Plant Growth Regul 32:337-344

Romanov GA, Spíchal L, Lomin SN et al (2005) A live cell hormonebinding assay on transgenic bacteria expressing a eukaryotic receptor protein. Anal Biochem. https://doi.org/10.1016/j.ab. 2005.09.012

Romanov GA, Lomin SN, Schmülling T (2006) Biochemical characteristics and ligand-binding properties of Arabidopsis cytokinin receptor AHK3 compared to CRE1/AHK4 as revealed by a direct binding assay. J Exp Bot. https://doi.org/10.1093/jxb/erl179

Romanov GA, Lomin SN, Schmülling T (2018) Cytokinin signaling: from the ER or from the PM? That is the question! New Phytol 218(1):41-53

Sakakibara H (2006) CYTOKININS: activity, biosynthesis, and translocation. Annu Rev Plant Biol. https://doi.org/10.1146/annurev. arplant.57.032905.105231

Sambrook J, Russell DW, Fritsch EF, Maniatis T (1989) Molecular cloning: a laboratory manual. Cold Spring Harbor Laboratory Press, Cold Spring Harbor

Sangwan RS, Sangwan-Norreel BS, Harada H (1997) In vitro techniques and plant morphogenesis: Fundamental aspects and practical applications. Plant Biotechnol 14:93-100

Schmitz RY, Skoog F (1970) The use of dimethylsulfoxide as a solvent in the tobacco bioassay for cytokinins. Plant Physiol 45:537-538

Schmülling T, Werner T, Riefler M et al (2003) Structure and function of cytokinin oxidase/dehydrogenase genes of maize, rice, Arabidopsis and other species. J Plant Res 116(3):241-252

Spíchal L, Rakova NY, Riefler M et al (2004) Two cytokinin receptors of Arabidopsis thaliana, CRE1/AHK4 and AHK3, differ in their ligand specificity in a bacterial assay. Plant Cell Physiol 45:12991305. https://doi.org/10.1093/pcp/pch132

Stolz A, Riefler M, Lomin SN et al (2011) The specificity of cytokinin signalling in Arabidopsis thaliana is mediated by differing ligand affinities and expression profiles of the receptors. Plant $\mathrm{J}$ 67:157-168. https://doi.org/10.1111/j.1365-313X.2011.04584.x

Suzuki T, Miwa K, Ishikawa K et al (2001) The Arabidopsis sensor His-kinase, AHK4, can respond to cytokinins. Plant Cell Physiol 42:107-113. https://doi.org/10.1093/pcp/pce037

The Jmol Team (2007) Jmol: an open-source Java viewer for chemical structures in 3D. http://jmolsourceforgenet

To JPC, Haberer G, Ferreira FJ et al (2004) Type-A Arabidopsis response regulators are partially redundant negative regulators of cytokinin signaling. Plant Cell 16:658-671. https://doi.org/10. $1105 /$ tpc. 018978.2

Trigiano RN, Gray DJ (2011) Plant tissue culture, development and biotechnology. CRC Press, Boca Raton

Ueguchi C, Koizumi H, Suzuki T, Mizuno T (2001) Novel family of sensor histidine kinase genes in Arabidopsis thaliana. Plant Cell Physiol 42:231-235

van Aalten DM, Bywater R, Findlay JB et al (1996) PRODRG, a program for generating molecular topologies and unique molecular descriptors from coordinates of small molecules. J Comput Aided Mol Des 10:255-262. https://doi.org/10.1007/BF00355047

Vasil IK (2008) A history of plant biotechnology: from the cell theory of Schleiden and Schwann to biotech crops. Plant Cell Rep 27:1423-1440

Wang J, Wang W, Kollman PA, Case DA (2006) Automatic atom type and bond type perception in molecular mechanical calculations. J Mol Graph Model 25:247-260. https://doi.org/10.1016/j.jmgm. 2005.12.005

Wulfetange K, Lomin SN, Romanov GA et al (2011) The cytokinin receptors of Arabidopsis are located mainly to the endoplasmic 
reticulum. Plant Physiol 156:1808-1818. https://doi.org/10.1104/ pp.111.180539

Yamada H, Suzuki T, Terada K et al (2001) The Arabidopsis AHK4 histidine kinase is a cytokinin-binding receptor that transduces cytokinin signals across the membrane. Plant Cell Physiol 42:1017-1023. https://doi.org/10.1093/pcp/pce127

Zhang X, Bremer H (1995) Control of the Escherichia coli rrnB P1 promoter strength by ppGpp. J Biol Chem 270:11181-11189. https://doi.org/10.1074/jbc.270.19.11181
Zhang K, Novak O, Wei Z et al (2014) Arabidopsis ABCG14 protein controls the acropetal translocation of root-synthesized cytokinins. Nat Commun 5:3274. https://doi.org/10.1038/ncomms4274

Publisher's Note Springer Nature remains neutral with regard to jurisdictional claims in published maps and institutional affiliations.

\section{Authors and Affiliations}

\section{Federica Brunoni ${ }^{1} \cdot$ Enrico Rolli ${ }^{1}$ Eugenia Polverini ${ }^{2}$ ED $\cdot$ Lukáš Spíchal $^{3}$ (i] $\cdot$ Ada Ricci $^{1}$ (1)}

$\triangle$ Ada Ricci

ada.ricci@unipr.it

1 Dipartimento Di Scienze Chimiche, Della Vita E Della Sostenibilità Ambientale, Università Di Parma, Parco Area delle Scienze 11/A, 43124 Parma, Italy

2 Dipartimento Di Scienze Matematiche, Fisiche E Informatiche, Università Di Parma, Parco Area delle Scienze 7/A, 43124 Parma, Italy
3 Department of Chemical Biology and Genetics, Centre of the Region Haná for Biotechnological and Agricultural Research, Faculty of Science, Palacký University, Šlechtitelů 27, 78371 Olomouc, Czech Republic 